\title{
Multilevel Governments' Decision-Making Process and Its Influencing Factors in Watershed Ecological Compensation
}

\author{
Xin Gao ${ }^{1, *}$, Juqin Shen ${ }^{1}$, Weijun He ${ }^{2}$, Fuhua Sun ${ }^{1}$, Zhaofang Zhang ${ }^{1}$, Xin Zhang ${ }^{3, *}$, \\ Liang Yuan ${ }^{2}$ and Min An ${ }^{2}$ \\ 1 Business School, Hohai University, Nanjing 211100, China; jqshen@hhu.edu.cn (J.S.); \\ fhsun@hhu.edu.cn (F.S.); zackzhang@hhu.edu.cn (Z.Z.) \\ 2 College of Economics \& Management, China Three Gorges University, Yichang 443002, China; \\ weijunhe@ctgu.edu.cn (W.H.); liangyuan@ctgu.edu.cn (L.Y.); anmin@hhu.edu.cn (M.A.) \\ 3 International Economic \&Technical Cooperation and Exchange Center, Ministry of Water Resources, \\ Beijing 100038, China \\ * Correspondence: gxtz1987@hhu.edu.cn (X.G.); lindazhangxin@126.com (X.Z.); \\ Tel.: +86-155-4931-4421 (X.G.); +86-010-63202362 (X.Z.)
}

Received: 3 March 2019; Accepted: 28 March 2019; Published: 3 April 2019

\begin{abstract}
Transboundary water pollution is a long-standing problem in China, although the Chinese government has been committed to the protection of water resources. Due to the different interests of multilevel governments and the regionalization of management, there is still no unified plan to solve the transboundary water pollution in China. Watershed ecological compensation as a holistic plan to deal with transboundary water pollution is being promoted currently. Taking the South-to-North Water Transfer Project' eastern route as an example, this paper firstly analyses stakeholders' strategies and establishes a tripartite game model based on evolutionary game theory. Secondly, by introducing Cobb Douglas production function creatively, the supervision level of the central government is refined into supervisory attitude and supervisory skills. Thirdly, the numerical simulation is used to analyze the sensitivity of influencing factors. The results show that: (1) whether the central government supervises the local governments mainly depends on the benefits of water environment improvement and supervision costs; (2) the initial negotiation plan of the stakeholders has a significant impact on their optimum strategies; (3) the fines imposed by the central government on the local governments have a small impact on the stable state of the system; (4) the higher the eco-compensation fee, the lower their likelihood of cooperation; (5) the central government's supervisory attitude and supervisory skills have significant effect on the sustainability of the optimum arrangement, even when willingness of upstream and downstream governments to cooperate is low; (6) the initial ecological benefits of downstream governments have no effect on the optimum strategy. Therefore, considering these insights is helpful to improve the watershed ecological compensation mechanism in order to solve transboundary water pollution and achieve the sustainability of water resources.
\end{abstract}

Keywords: transboundary water pollution; watershed ecological compensation; sustainability; water resources; South-to-North Water Transfer Project; Eastern Route; stakeholders; evolutionary game theory

\section{Introduction}

Water resources are indispensable strategic resources for social and economic development [1]. While the development of society, economy, and environment depends on water resources [2,3], it also 
pollutes water resources. Because of the mobility of water resources, water pollution will affect many administrative regions [4]. Therefore, water pollution is not a problem of governance in an administrative region, but a transboundary problem involving multiple administrative regions [5].

Transboundary water pollution refers to the pollutants produced in the upstream regions, which are discharged into rivers or lakes, and then affects the ecological environment of the downstream regions with water $[4,6]$. At present, many scholars have studied the problem of transboundary water pollution and put forward many solutions. Silva and Caplan [7] analyzed the effectiveness of the federal policy on transboundary pollution control. They believed that the central government could achieve greater social benefits when it acted as the leader of transboundary pollution control. Xia [8] compared the water law from international and EU, suggested that China should set up a basic legal system to solve transboundary water pollution. Zhao et al. [5] calculated the optimal pollutant transfer tax by constructing the transfer tax model and combining the geographical structure of the basin.

Governments in different regions have different interests and actions, which makes the problem of transboundary water pollution difficult to solve. In recent years, as a new method, payments for ecosystem services (PES) has been proposed to solve transboundary water pollution. PES is a transparent system for the provision of environmental services through conditional payments to voluntary providers [9,10], which is been widely used in natural resource management and environmental management like forest protection [11], land conservation [12], and water resources [13,14]. Payments for watershed ecosystem services (PWES) is an example of applying PES to water resources, such as the Ganjiang River Basin [15-17] and Taihu River Basin [18,19]. In China, there is a system similar to PWES, which is called a watershed ecological compensation system. It is based on the principle of "who develops, who protects; who destroys, who restores; who benefits, who compensates; who pollutes, who pays" [20] and the advantage of this system is to coordinate interests among multilevel governments through transfer payments, promote their cooperation, and then to solve the problem of transboundary water pollution, achieve the sustainable development of water resources [21-23]. How to improve watershed ecological compensation system and promote multilevel governments' cooperation to solve transboundary water pollution is a hot issue. Therefore, the study of multilevel governments' decision-making behaviors and its influencing factors will help to improve the watershed ecological compensation system to solve transboundary water pollution.

So far, there are three methods to study the influencing factors of watershed ecological compensation in the academic research: (1) Game theory, which is the study of mathematical models of strategic interaction between rational decision-makers [24]. Qu et al. [25] constructed a static game model between upstream and downstream governments to study the problems of watershed ecological compensation and found that local governments couldn't spontaneously implement the ecological compensation system. Jie et al. [26] assumed that the central government's supervision is constant. On this basis, they constructed an evolutionary game model between upstream and downstream governments and concluded that penalties, the ecological compensation fee and initial costs affected the cooperation. Cao et al. [27] build the game theory model to analyze marine ecological compensation and they found energy conservation and emission reduction affected the optimal amount of capital investment of environmental protection. (2) Contingent valuation method (CVM), which is a method of measuring the value of goods or services by investigating the economic behavior of respondents in hypothetical markets directly using questionnaires to obtain consumers' willingness to pay [28]. Willingness to pay (WTP) is the maximum price at or below which a consumer will definitely buy one unit of a product or service and it is one of the main applications of CVM. Bhandari et al. [29] used the CVM to study residents' WTP for the lower reaches of the Chure region in Nepal and found that beneficiaries living downstream of the basin were willing to pay more for drinking water services if water quality can be guaranteed and sustained, as well as quantity guarantee to the critical infrastructure operation [30]. (3) Bayesian network studies the interdependent statistical regularity among multiple variables objectively, and visually expressing the causal correlations among random variables in the graph. Peng et al. [31] used Bayesian network to study the dependencies of variables 
extracted by CVM and found that the factors influencing public support for the project, willingness to participate in public benefit actives and public cognition of water scarcity were crucial to WTP.

Existing researches provide certain insights into behavioral change and influencing factors of watershed ecological compensation, but they have some limitations: (1) static game analysis cannot reflect the changes in subject's behavior; (2) most literature mainly focuses on the two-party game between upstream and downstream governments, but seldom consider the tripartite game that includes the central government $[25,26]$. Even though some scholars have also proposed the supervision of the central government, they only consider it as an invariable exogenous variable [26]. But the central government's supervision is not constant. (3) CVM and Bayesian network cannot be used to reflect the subjects' behaviors while studying the influencing factors.

Evolutionary game theory is mainly used in decision-making among multi-stakeholders and the process of stakeholders' behavioral changes [32-35]. Firstly, watershed ecological compensation involves multilevel governments. It is difficult for them to determine their optimal strategies in a game, so they need to revise their strategies in continuous games to reach their optimal state. Secondly, previous scholars used a two-party game without considering the central government or assuming that the supervision of the central government is constant $[25,26]$. It is inconsistent with the facts. Therefore, to fill this research gap, this paper introduces the evolutionary game theory and simulation to study multilevel governments' decision-making process and influencing factors in the watershed ecological compensation. Adding the central government to the game makes it closer to the facts.

This paper mainly makes the following contributions: (1) according to the behavioral characteristics of stakeholders, using a tripartite evolutionary game model to study the evolution strategies; (2) adding constraints, studying the evolutionary process of stakeholders in two programs; (3) analyzing the sensitivity of influencing factors by simulation; (4) introducing Cobb Douglas production function, taking the central government's supervisory attitude and supervisory skills as input and getting the supervision level of the central government in order to analyze the possibility whether the central government can detect and punish the unilateral breach of contract for local governments; (5) considering the differences of transaction costs, ecological benefits and fines between upstream and downstream governments.

The rest of this paper is structured as follows. Section 2 introduces the study area and theory background. Section 3 proposes the hypothesis, establishes a tripartite game model and calculates the optimum state of the model by adding constraints. Section 4 makes sensitivity analysis of parameters using simulation. Section 5 discusses the results, states the limitations and summarizes future works. Section 6 gets conclusions and offers suggestions to multilevel governments.

\section{Method}

\subsection{Study Area}

As a water-scarce country, China's per capita water resources are only a quarter of the world's per capita water resources [36]. About $40 \%$ of China's population live in water-scarce areas. Because of the spatial difference of water resources distribution in China [37-39], the Chinese government has decided to build the South-to-North Water Transfer Project (SNWTP), which is aimed to transfer the abundant water resources from the South to the North.

SNWTP is divided into three different routes, namely, the Eastern Route, the Middle Route and the Western Route. The starting point of the Eastern Route is Jiangdu Water Conservancy Project in Yangzhou City, Jiangsu Province. The Middle Route starts from Danjiangkou Reservoir in Hubei Province and the Western Route is yet to be constructed. Through three routes of SNWTP, the Yangtze River, Yellow River, Huaihe River, and Haihe River are linked together [40] (Figure 1). In 2013, the first phase of the Eastern Route was completed.

The Eastern Route runs through several provinces. Most of the cities in these regions have developed rapidly, producing about $35 \%$ of China's GDP [41]. However, the actual situation is 
that the water quality of the Eastern Route shows a declining trend and the rapid development of manufacturing industry in the upstream areas has led to large amounts of untreated sewage being discharged into rivers and lakes, especially the increase of industrial point source pollution and agricultural non-point source pollution. Due to the poor management of water resources by multilevel governments, this scenario has deteriorated the water quality in the downstream areas of the Eastern Route [32]. As transboundary water pollution exists along the Eastern Route of SNWTP, this paper will take the Eastern Route of SNWTP as an example.

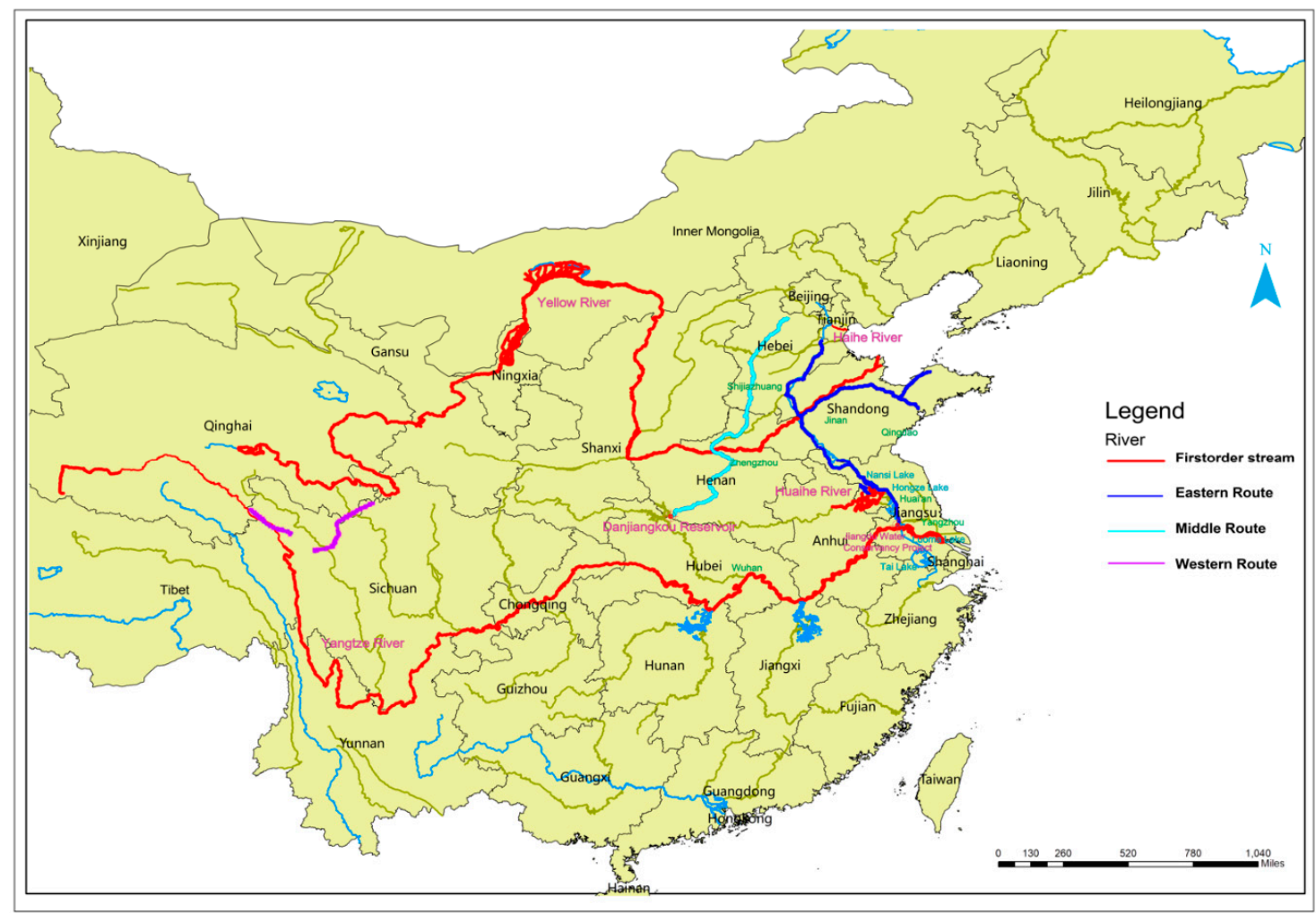

Figure 1. Three routes of South-to-North Water Transfer Project.

\subsection{Theory Background}

The evolutionary game theory originated from Darwin's biological evolution theory and Lamarck's genetic theory. It holds that the participants in the game are not completely rational, but bounded rational. Participants in the game do not believe that one of their actions will affect their opponents' choices. Participants' decisions are based on long-term observations of their opponents. Under this theory, groups are regarded as the subjects of the research. It pays attention to the process that individuals in the groups adjust their decision-making dynamically through imitation and learning, and finally reach a stable state $[42,43]$.

The development of evolutionary game theory has gone through three stages [44]. In the first stage, biologists introduce game theory, which is only applied in economics, into biology and construct a series of biological evolutionary models including plant growth, animal competition and gender distribution [45]. In the second stage, biologists introduced evolution into traditional game theory, transformed Nash equilibrium into evolutionary stabilization strategy, and constructed a replication dynamic model $[46,47]$. In the third stage, economists use biologists' ideas to develop evolutionary stable equilibrium to stochastic stable equilibrium and deterministic complex dynamic model to stochastic individual learning dynamic model [48-53].

The analysis structure of evolutionary game includes four parts: game framework, fitness function, evolutionary process and evolutionary stability strategy. 
(1) Game framework. It mainly refers to the structure and rules of the game. It holds that participants do not have all the knowledge of game structure and rules. That means participants' knowledge and information are limited. Moreover, participants usually acquire strategies through transmission mechanism rather than a rational choice [51].

(2) Fitness function. Fitness is the core concept of evolutionary theory, which is used to describe the reproductive capacity of genes. In the evolutionary game model, the fitness of a strategy can be understood as the growth rate of the number of people who adopt the strategy after each game. Fitness function can be simply regarded as the mapping relationship between game strategy and fitness.

(3) Evolution process. The evolutionary game differs from traditional game theory in that it studies the evolutionary process of group size and strategy frequency. The evolutionary process mainly includes a selection mechanism and the mutation mechanism [53].

(4) Evolutionary stabilization strategy. It is the most basic equilibrium concept in the evolutionary game [54]. The core idea is that there must be a positive intrusion barrier if an existing strategy is evolutionary stabilization equilibrium strategy. When the frequency of mutation strategy is lower than this barrier, the existing strategy can obtain higher benefits than mutation strategy.

\section{Model and Analysis}

\subsection{Stakeholders in the Eastern Route of SNWTP}

Based on the Environmental Protection Law in China, local governments have the responsibility to protect water resources and bear the primary responsibility for the water pollution within their jurisdiction. Meanwhile, as the superior of local governments, the central government does not only need to formulate the environmental policy but also need to supervise and manage them. Thus, only governments at different levels can join in the game and become the stakeholders in the watershed ecological compensation. According to the "Action Plan for Establishing Market-oriented and Diversified Mechanism for Ecological Compensation", which is published by National Development and Reform Commission, the central government encourages provincial administrative regions to establish the horizontal compensation system. In this system, the central government only carries out the functions of coordinating and supervising local governments [55]. Adding the central government to the game is more suitable for the actual situation in China and help to solve the problem. Therefore, there are three stakeholders in the tripartite game: upstream governments, downstream governments and the central government.

Because three different governments have different interests, this will affect their behaviors during the tripartite game.

Upstream governments: in order to guarantee water quality to downstream area, upstream governments have to protect water resources by prohibiting the development of the industry. But upstream governments have their own interests of promoting local economic by industry. It means that upstream governments can use water resources at its disposal.

Downstream governments: they should pay a compensation fee because upstream governments abandon development opportunities for protecting water resources. While downstream governments have the rights to use clean water, they should not pay a compensation fee.

Central government: the main interest is to get the maximum benefits by considering the social, economic and ecological efficiency in SNWTP. Meanwhile, the central government has to coordinate the interests between different governments to ensure the operation of SNWTP. So, the central government has the right to supervise upstream governments to protect water resources and request downstream governments to pay a compensation fee to the upstream. When the upstream and downstream governments fail to fulfill their responsibilities and obligations, the central government has the right to promote cooperation through various means, including punishing non-cooperation and rewarding 
cooperation. Meanwhile, the supervision level of the central government is restricted by its own supervision costs, overall benefits, supervisory attitude to water resources and supervisory skills.

The relationship of stakeholders in Eastern Route of SNWTP on watershed ecological compensation is shown in Figure 2.

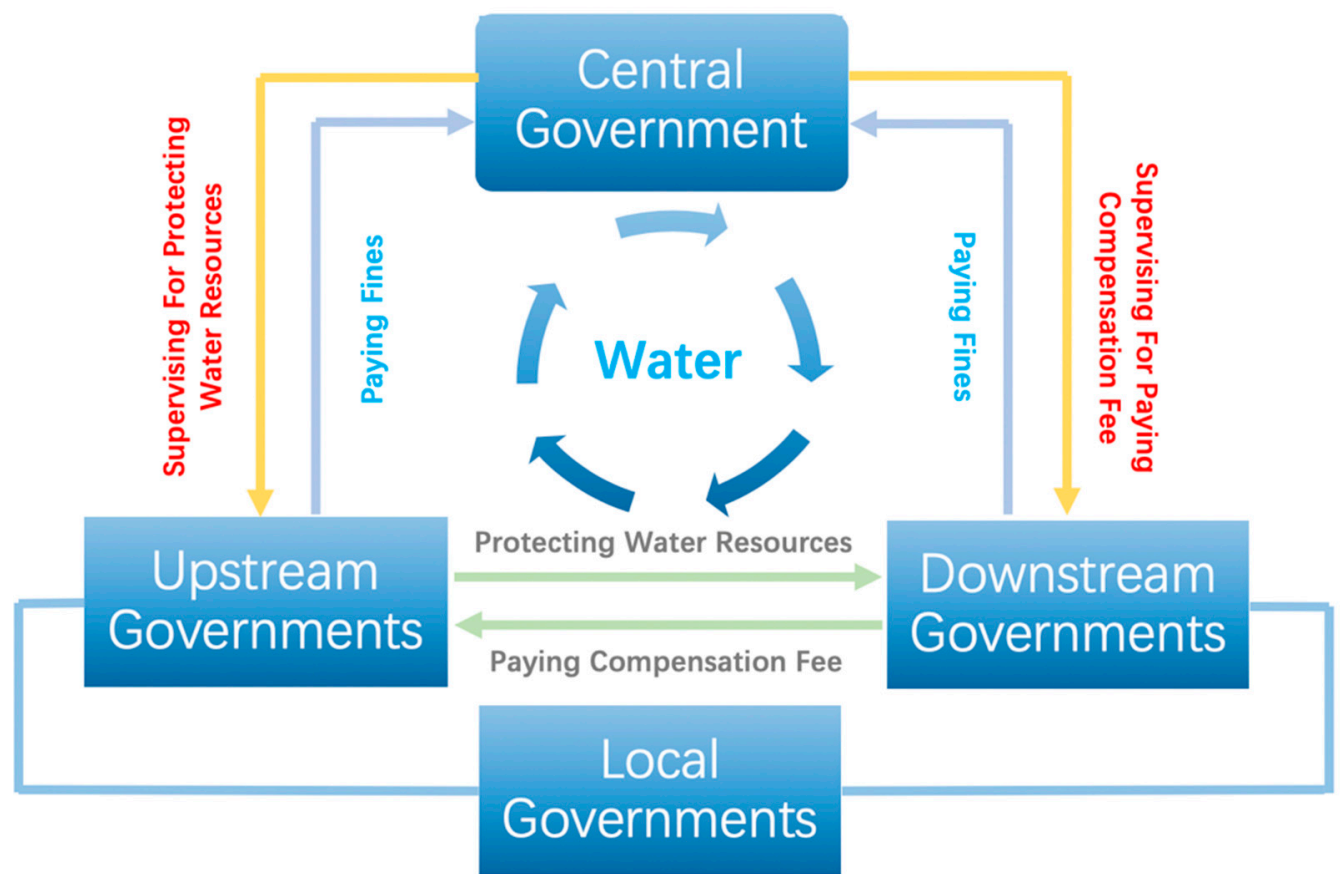

Figure 2. The relationship of stakeholders in eastern route of South-to-North Water Transfer Project (SNWTP).

\subsection{Evolutionary Game Model Construction}

\subsubsection{Hypothesis}

There are three players in the game of watershed ecological compensation in Eastern Route of SNWTP. These players are upstream governments, downstream governments and the central government. This paper assumes that:

(1) The power of upstream and downstream governments is equal, and the central government has the power to supervise and coordinate them.

(2) Upstream governments have two alternative strategies in its set of strategies, protecting water resources or not protecting.

(3) Downstream governments have two alternative strategies, paying a compensation fee to upstream governments or not paying.

(4) The central government also has two alternative strategies, supervising the local governments or not supervising.

(5) Upstream governments, downstream governments and the central government want to maximize their own benefits during the tripartite game [56].

(6) Upstream governments, downstream governments and the central government are not completely rational but bounded rational.

(7) Upstream governments, downstream governments and the central government usually cannot find their own optimal strategy at one time, but adjust their strategies in continuous games and ultimately achieve the optimal strategy.

(8) This paper only considers the unilateral default of upstream and downstream governments, assuming that bilateral default is impossible to occur. 
(9) The supervision level of the central government is mainly affected by the supervisory attitude to water resources and supervisory skills. If these factors are taken as input, according to the Cobb-Douglas production function $\left(Y=A L^{\alpha} K^{\beta}\right)$, the probability that the central government can find out the local government's unilateral breach of contract is $a \times b$, supposing $A=\alpha=$ $\beta=1, L=a, K=b$.

In the tripartite game of the Eastern Route of SNWTP, $C_{1}$ represents the direct costs for water resources protection of upstream governments; $C_{2}$ represents the opportunity costs for water resources protection of upstream governments; $C_{3}$ represents the supervision costs of the central government. $C_{S}$ and $C_{x}$ represent the transaction costs paid by upstream and downstream governments when they choose to cooperate. $F_{1}$ and $F_{2}$ represent the fines imposed by the central government on the upstream and downstream governments when the local governments default unilaterally. $L_{1}$ and $L_{2}$ represent the initial ecological benefits of downstream governments when upstream governments choose to protect water resources or not. $M$ and $M_{1}$ represent the additional benefits that local governments gain owing to the improvement of the water environment when the upstream and downstream governments cooperate with each other. $R$ represents the ecological compensation fee to upstream governments for protecting water resources. $R_{1}$ represents the overall benefits of the central government. The parameter of $a$ represents the supervisory attitude to water resources and $b$ represents the supervisory skills of the central government. Table 1 shows the parameters specifications.

Table 1. The parameters in the tripartite game (all parameters are positive).

\begin{tabular}{cc}
\hline Parameters & Description \\
\hline$C_{1}$ & Direct costs of upstream governments \\
$C_{2}$ & Opportunity costs of upstream governments \\
$C_{3}$ & Supervision costs of the central government \\
$C_{\mathrm{S}}$ & Transaction costs of upstream governments \\
$C_{\mathrm{x}}$ & Transaction costs of downstream governments \\
$F_{1}$ & Fines of unilateral default for upstream governments \\
$F_{2}$ & Fines of unilateral default for downstream governments \\
$L_{1}$ & Initial ecological benefits of downstream governments when upstream \\
$L_{2}$ & governments protect the water resources \\
$M$ & Initial ecological benefits of downstream governments when upstream \\
$M_{1}$ & governments don't protect the water resources \\
$R$ & Additional benefits of upstream governments \\
$R_{1}$ & Additional benefits of downstream governments \\
$a$ & Ecological compensation fee \\
$b$ & Benefits of the central government \\
\hline
\end{tabular}

\subsubsection{Payoffs of Stakeholders}

There are two strategies for the central government, supervising the local governments or not supervising. If $z$ indicates the probability that the central government will supervise the local governments, then $1-z$ indicates the probability of not supervising.

\section{Program with Supervision}

The parameters of $x$ and $y$ indicate the probabilities that upstream governments choose to protect water resources and downstream governments choose to pay a compensation fee. $U_{m n k}, D_{m n k}$ and $G_{m n k}$ represent the payoffs of upstream governments, downstream governments and the central government in different strategies. $m, n$, and $k$ represent the strategies of upstream governments, downstream governments and the central government respectively. Table 2 shows the specifications of $m, n$, and $k$. 
Table 2. The specifications of $m, n$, and $k$.

\begin{tabular}{cccc}
\hline Governments & Symbol & Value & Strategies \\
\hline Upstream governments & $m$ & 1 & Protecting water resources \\
Downstream & $n$ & 1 & Not protecting water resources \\
governments & & 2 & Paying for a compensation fee \\
The Central government & $k$ & 1 & Not paying for a compensation fee \\
& & 2 & Supervision \\
\hline
\end{tabular}

1. The payoffs of upstream governments.

When downstream governments choose to pay a compensation fee and upstream governments choose to protect water resources or not to protect, the payoffs of upstream governments are:

$$
\begin{gathered}
U_{111}=R+M-C_{1}-C_{2}-C_{s} \\
U_{211}=R-a \times b \times F_{1}
\end{gathered}
$$

When downstream governments choose not to pay the compensation fee and upstream governments choose to protect water resources or not to protect, the payoffs of upstream governments are:

$$
\begin{gathered}
U_{121}=-C_{1}-C_{2}-C_{s} \\
U_{221}=0
\end{gathered}
$$

2. The payoffs of downstream governments.

When upstream governments choose to protect water resources and downstream governments choose to pay compensation fee or not to pay, the payoffs of downstream governments are:

$$
\begin{gathered}
D_{111}=L_{1}+M_{1}-R-C_{x} \\
D_{121}=L_{1}-a \times b \times F_{2}
\end{gathered}
$$

When upstream governments choose not to protect water resources and downstream governments choose to pay compensation fee or not to pay, the payoffs of downstream governments are:

$$
\begin{gathered}
D_{211}=L_{2}-R-C_{x} \\
D_{221}=L_{2}
\end{gathered}
$$

3. The payoffs of the central government.

When upstream governments protect water resources and downstream governments choose to pay the compensation fee or not to pay, the payoffs of the central government are:

$$
\begin{gathered}
G_{111}=R_{1}-C_{3} \\
G_{121}=R_{1}-C_{3}+a \times b \times F_{2}
\end{gathered}
$$

When upstream governments choose not to protect water resources and downstream governments pay the compensation fee or not to pay, the payoffs of the central government are:

$$
\begin{gathered}
G_{211}=a \times b \times F_{1}-C_{3} \\
G_{221}=-C_{3}
\end{gathered}
$$


Table 3 shows the payoff matrix of the stakeholders with the supervision of the central government.

Table 3. Payoffs matrix of the stakeholders with supervision of the central government.

\begin{tabular}{|c|c|c|c|c|c|c|c|}
\hline \multicolumn{8}{|c|}{ When the Central Government Supervise the Local Governments } \\
\hline & & \multicolumn{6}{|c|}{ Downstream Governments } \\
\hline & & \multicolumn{3}{|c|}{ Paying for a Compensation Fee } & \multicolumn{3}{|c|}{ Not Paying for a Compensation Fee } \\
\hline & & $\begin{array}{l}\text { Upstream } \\
\text { Governments }\end{array}$ & $\begin{array}{l}\text { Downstream } \\
\text { Governments }\end{array}$ & $\begin{array}{c}\text { Central } \\
\text { Government }\end{array}$ & $\begin{array}{l}\text { Upstream } \\
\text { Governments }\end{array}$ & $\begin{array}{l}\text { Downstream } \\
\text { Governments }\end{array}$ & $\begin{array}{c}\text { Central } \\
\text { Government }\end{array}$ \\
\hline $\begin{array}{l}\text { Upstream } \\
\text { governments }\end{array}$ & $\begin{array}{l}\text { Protecting water } \\
\text { resources } \\
\text { Not protecting } \\
\text { water resources }\end{array}$ & $\begin{array}{c}R+M- \\
C_{1}-C_{2}-C_{S} \\
R-a \times b \times \\
F_{1}\end{array}$ & $\begin{array}{c}L_{1}+M_{1}- \\
R-C_{x} \\
L_{2}-R-C_{x}\end{array}$ & $\begin{array}{c}R_{1}-C_{3} \\
a \times b \times F_{1}- \\
C_{3}\end{array}$ & $\begin{array}{c}-C_{1}-C_{2}- \\
C_{s} \\
0\end{array}$ & $\begin{array}{c}L_{1}-a \times b \times \\
F_{2} \\
L_{2}\end{array}$ & $\begin{array}{l}R_{1}-C_{3}+ \\
a \times b \times F_{2} \\
\quad-C_{3}\end{array}$ \\
\hline
\end{tabular}

Notes: $C_{1}$ represents direct costs of upstream governments; $C_{2}$ represents opportunity costs to upstream governments; $C_{3}$ represents supervision costs of the central government; $C_{s}$ represents transaction costs of upstream governments; $C_{\mathrm{x}}$ represents transaction costs of downstream governments; $F_{1}$ represents fines to upstream governments; $F_{2}$ represents fines to downstream governments; $L_{1}$ and $L_{2}$ represent initial ecological benefits of downstream governments when upstream governments protect the water resources or not protect. $M$ represents additional benefits of upstream governments; $M_{1}$ represents additional benefits of downstream governments; $R$ represents the ecological compensation fee; $R_{1}$ represents benefits of the central government; $a$ represents supervisory attitude towards water resources; $b$ represents supervisory skills.

Program without Supervision

1. The payoffs of upstream governments.

When downstream governments choose the strategy of paying compensation fee and upstream governments choose to protect water resources or not to protect, the payoffs of upstream governments are:

$$
\begin{gathered}
U_{112}=R+M-C_{1}-C_{2}-C_{s} \\
U_{212}=R
\end{gathered}
$$

When downstream governments choose not to pay the compensation fee and upstream governments choose to protect water resources or not to protect, the payoffs of upstream governments are:

$$
\begin{gathered}
U_{121}=-C_{1}-C_{2}-C_{s} \\
U_{221}=0
\end{gathered}
$$

2. The payoffs of downstream governments.

When upstream governments choose to protect water resources and downstream governments choose to pay compensation fee or not to pay, the payoffs of downstream governments are:

$$
\begin{gathered}
D_{111}=L_{1}+M_{1}-R-C_{x} \\
D_{121}=L_{1}
\end{gathered}
$$

When upstream governments choose not to protect water resources and downstream governments choose to pay compensation fee or not to pay, the payoffs of downstream governments are:

$$
\begin{gathered}
D_{211}=L_{2}-R-C_{x} \\
D_{221}=L_{2}
\end{gathered}
$$

3. The payoffs of the central government. 
Without the supervision of the central government, whatever strategy the upstream and downstream governments choose, the payoff of the central government are:

$$
G_{112}=G_{212}=G_{121}=G_{221}=0
$$

Table 4 shows the payoffs matrix of the stakeholders without the supervision of the central government.

Table 4. Payoffs matrix of the stakeholders without supervision of the central government.

\begin{tabular}{|c|c|c|c|c|c|c|c|}
\hline \multicolumn{8}{|c|}{ When the Central Government Do Not Supervise the Local Governments } \\
\hline & & \multicolumn{6}{|c|}{ Downstream Governments } \\
\hline & & \multicolumn{3}{|c|}{ Paying for a Compensation Fee } & \multicolumn{3}{|c|}{ Not Paying for a Compensation Fee } \\
\hline & & $\begin{array}{l}\text { Upstream } \\
\text { Governments }\end{array}$ & $\begin{array}{l}\text { Downstream } \\
\text { Governments }\end{array}$ & $\begin{array}{c}\text { Central } \\
\text { Government }\end{array}$ & $\begin{array}{c}\text { Upstream } \\
\text { Governments }\end{array}$ & $\begin{array}{l}\text { Downstream } \\
\text { Governments }\end{array}$ & $\begin{array}{c}\text { Central } \\
\text { Government }\end{array}$ \\
\hline \multirow[t]{2}{*}{$\begin{array}{l}\text { Upstream } \\
\text { governments }\end{array}$} & $\begin{array}{l}\text { Protecting water } \\
\text { resources }\end{array}$ & $\begin{array}{c}R+M- \\
C_{1}-C_{2}-C_{s}\end{array}$ & $\begin{array}{c}L_{1}+M_{1}- \\
R-C_{x}\end{array}$ & 0 & $\begin{array}{c}-C_{1}-C_{2}- \\
C_{S}\end{array}$ & $L_{1}$ & 0 \\
\hline & $\begin{array}{l}\text { Not protecting } \\
\text { water resources }\end{array}$ & $R$ & $L_{2}-R-C_{x}$ & 0 & 0 & $L_{2}$ & 0 \\
\hline
\end{tabular}

Notes: $C_{1}$ represents direct costs of upstream governments; $C_{2}$ represents opportunity costs to upstream governments; $C_{S}$ represents transaction costs of upstream governments; $C_{\mathrm{x}}$ represents transaction costs of downstream governments; $L_{1}$ and $L_{2}$ represent initial ecological benefits of downstream governments when upstream governments protect the water resources or not protect. $M$ represents additional benefits of upstream governments; $M_{1}$ represents additional benefits of downstream governments; $R$ represents ecological compensation fee.

\subsubsection{Replicated Dynamic Equations}

The variables $\pi_{11}$ and $\pi_{12}$ represent the expected payoffs of upstream governments choosing different strategies. The variable $\bar{\pi}_{1}$ indicates the average expected payoffs of upstream governments. Therefore,

$$
\begin{gathered}
\pi_{11}=y \times z \times( \\
\left.++R-C_{1}-C_{2}-C_{S}\right)+(1-y) \times z \times\left(-C_{1}-C_{2}-C_{S}\right) \\
+y \times(1-z) \times\left(M+R-C_{1}-C_{2}-C_{S}\right) \\
+(1-y) \times(1-z) \times\left(-C_{1}-C_{2}-C_{S}\right) \\
\pi_{12}=y \times z \times\left(R-a \times b \times F_{1}\right)+(1-y) \times z \times 0+y \times(1-z) \times R+(1-y) \times(1-z) \times 0 \\
\pi_{1}=x \times \pi_{11}+(1-x) \times \pi_{12} \\
=y \times R-\mathrm{x} \times\left(C_{1}+C_{2}+C_{S}\right)+x \times y \times M-a \times b \times y \times z \times F_{1}+a \times b \times x \times y \times z \times F_{1}
\end{gathered}
$$

The replicated dynamic equation of upstream governments is as follows:

$$
F_{1}(x)=\frac{d x}{d t}=x \times\left(\pi_{11}-\overline{\pi_{1}}\right)=x \times(x-1) \times\left(C_{1}+C_{2}+C_{s}-y \times M-a \times b \times y \times z \times F_{1}\right)
$$

For downstream governments, we use the variables $\pi_{21}, \pi_{22}$ and $\pi_{2}$ to represent the expected payoffs of paying for the compensation fee, not paying and the average expected payoffs, respectively.

$$
\begin{gathered}
\pi_{21}=x \times z \times\left(L_{1}+M_{1}-R-C_{x}\right)+(1-x) \times z \times\left(L_{2}-R-C_{x}\right) \\
+x \times(1-z) \times\left(L_{1}+M_{1}-R-C_{x}\right)+(1-x) \times(1-z) \times\left(L_{2}-R-C_{x}\right) \\
\pi_{22}=x \times z \times\left(L_{1}-a \times b \times F_{2}\right)+(1-x) \times z \times L_{2}+x \times(1-z) \times L_{1}+(1-x) \times(1-z) \times L_{2} \\
\overline{\pi_{2}}=y \times \pi_{21}+(1-y) \times \pi_{22} \\
=L_{2}+x \times\left(L_{1}-L_{2}\right)-y \times\left(R+C_{x}\right)+x \times y \times M_{1}-a \times b \times x \times z \times F_{2} \\
+a \times b \times x \times y \times z \times F_{2}
\end{gathered}
$$


The replicated dynamic game equation of downstream governments is as follows:

$$
F_{2}(y)=\frac{d y}{d t}=y \times\left(\pi_{21}-\overline{\pi_{2}}\right)=y \times(y-1) \times\left(C_{x}+\mathrm{R}-x \times M_{1}-a \times b \times x \times z \times F_{2}\right)
$$

The analysis is the same as above, $\pi_{31}$ and $\pi_{32}$ represent the expected payoffs of the central government choosing the strategies of supervision and non-supervision. $\overline{\pi_{3}}$ indicates the average expected payoff of the central government.

$$
\begin{aligned}
\pi_{31}=x \times y \times & \left(R_{1}-C_{3}\right)+(1-x) \times y \times\left(a \times b \times F_{1}-C_{3}\right)+x \times(1-y) \times \\
\left(R_{1}+a \times b \times F_{2}-C_{3}\right)+(1-x) \times(1-y) \times\left(-C_{3}\right) & \\
\pi_{32}=0 & \\
\overline{\pi_{3}}=z \times \pi_{31}+\quad & (1-z) \times \pi_{32} \\
& =x \times y \times z \times\left(R_{1}-C_{3}\right)+(1-x) \times y \times z \times\left(a \times b \times F_{1}-C_{3}\right) \\
& +x \times(1-y) \times z \times\left(R_{1}+a \times b \times F_{2}-C_{3}\right) \\
& +(1-x) \times(1-y) \times z \times\left(-C_{3}\right)
\end{aligned}
$$

The replicated dynamic game equation of central governments is as follows:

$$
\begin{aligned}
F_{3}(z)=\frac{d z}{d t}=z \times & \left(\pi_{31}-\overline{\pi_{3}}\right) \\
& =z \times(z-1) \\
& \times\left(C_{3}-x \times R_{1}-\mathrm{a} \times \mathrm{b} \times x \times F_{2}-\mathrm{a} \times \mathrm{b} \times \mathrm{y} \times F_{1}+a \times b \times x \times y \times F_{1}\right. \\
& \left.+a \times b \times x \times y \times F_{2}\right)
\end{aligned}
$$

Equations (25), (29) and (33) constitute the system of the tripartite dynamic game. According to the hypothesis (6) and (7), these stakeholders are bounded rationality. It is hard for them to choose the best strategy at one time. Meanwhile, the initial probabilities of three stakeholders change through time. So, they will change their strategies over time until they reach a steady state. This steady state is called the evolutionary stable strategy (ESS).

\subsubsection{Evolutionary Stable Strategies}

Equilibrium Points of the Tripartite Evolutionary Game Model

According to the system of tripartite dynamic evolutionary game model, the initial probabilities of three stakeholders $(x, y, z)$ depend on time $(t)$. It means $x, y$ and $z$ can change over time. Thus, the value of $x(t), y(t)$, and $z(t)$ are between 0 and 1 . In order to solve differential equations in dynamic systems, the initial values of $x, y$ and $z$ need to be set, namely $x(0), y(0)$ and $z(0)$. In this framework, for a random initial value, the calculated $x(t), y(t)$ and $z(t)$ will form a mixed strategy of the tripartite evolutionary game.

What we are most interested in is the stable state of the tripartite evolutionary game. In order to obtain a stable state, we make the three differential equations in the dynamic system equal 0 and then solve to obtain the solution for the optimum state. That is

$$
\begin{aligned}
& F_{1}(x)=\frac{d x}{d t}=x \times(x-1) \times\left(C_{1}+C_{2}+C_{s}-y \times M-a \times b \times y \times z \times F_{1}\right)=0 \\
& F_{2}(y)=\frac{d y}{d t}=y \times(y-1) \times\left(C_{x}+R-x \times M_{1}-a \times b \times x \times z \times F_{2}\right)=0 \\
& F_{3}(z)=\frac{d z}{d t}=z \times(z-1) \\
& \times\left(C_{3}-x \times R_{1}-a \times b \times x \times F_{2}-a \times b \times y \times F_{1}+a \times b \times x \times y \times F_{1}+a \times b \times x \times y \times F_{2}\right)
\end{aligned}
$$

By solving Equation (34), we obtain all equilibrium points, namely $E_{1}(0,0,0), E_{2}(1,0,0), E_{3}(0$, $1,0), E_{4}(0,0,1), E_{5}(1,1,0), E_{6}(1,0,1), E_{7}(0,1,1)$, and $E_{8}(1,1,1)$. These eight points constitute the boundary of the solution of dynamic evolution system, and then form the space of solution, which is $x(t) \in(0,1), y(t) \in(0,1), z(t) \in(0,1)[13,29]$. So, the values of $x(t), y(t)$ and $z(t)$ can only be taken 
in this space. And there is another equilibrium point in this dynamic evolution system, namely $E_{9}$. Solving Equation (35), we can get the last equilibrium point $E_{9}$.

$$
\left\{\begin{array}{c}
\left(C_{1}+C_{2}+C_{s}-y \times M-a \times b \times y \times z \times F_{1}\right)=0 \\
\left(C_{x}+\mathrm{R}-x \times M_{1}-a \times b \times x \times z \times F_{2}\right)=0 \\
\left(C_{3}-x \times R_{1}-\mathrm{a} \times \mathrm{b} \times x \times F_{2}-\mathrm{a} \times \mathrm{b} \times \mathrm{y} \times F_{1}+a \times b \times x \times y \times F_{1}+a \times b \times x \times y \times F_{2}\right)=0
\end{array}\right.
$$

Stability of Equilibrium Points

According to the framework of evolutionary game theory [54], in the replication dynamic system of the tripartite evolutionary game, the necessary condition for a strategy combination to be asymptotically stable is that the strategy combination must be a strict Nash equilibrium [43]. Thus, if the equilibrium point is asymptotically stable (called it an asymptotically stable equilibrium point or sink) [57], then the equilibrium point must be a strict Nash equilibrium, and the strict Nash equilibrium is also a pure-strategy Nash equilibrium. Because $E_{9}$ is a mixed strategy Nash equilibrium in this replication dynamic system, it is not a sink. Therefore, we only need to focus on the other eight equilibrium points and analyze them. According to Friedman [51], the Jacobian matrix of replication dynamic system is helpful to judge whether equilibrium points are the sink. Thus, we get eight Jacobian matrixes of eight points, namely $J_{1}$ to $J_{8}$, and they are listed in Appendix A.

According to Lyapunov's System Stability Theory [58], when all eigenvalues of a matrix are negative, the system is asymptotically stable; when all eigenvalues of a matrix are less than or equal to zero and the eigenvalues equaling to 0 have no multiple roots, the system is stable in the sense of Lyapunov; when one eigenvalue of a matrix is greater than zero or the eigenvalues equaling to 0 have multiple roots, the system is unstable [59].

Because all parameters are positive, we can find that $E_{1}$ is asymptotically stable; $E_{2}, E_{3}, E_{4}, E_{6}$, and $E_{7}$ are unstable; $E_{5}$ and $E_{8}$ can be judged by adding constraints. Comparing $J_{5}$ with $J_{8}$, they are mutually exclusive. When $E_{5}$ is stable, $E_{8}$ is unstable; when $E_{8}$ is stable, $E_{5}$ is unstable. When the eigenvalues of $J_{5}$ are negative, the eigenvalues of $J_{8}$ are negative. The most important is to judge the values of $C_{3}$ and $R_{1}$. Thus, there are two games in the watershed ecological compensation in Eastern Route of SNWTP.

Game 1. When the constraints satisfy the inequalities group (36), there are two sinks ( $E_{1}$ and $\left.E_{5}\right)$ in this tripartite evolutionary game.

$$
\left\{\begin{array}{c}
C_{1}+C_{2}+C_{s}-M<0 \\
C_{x}-M_{1}+R<0 \\
R_{1}-C_{3}<0
\end{array}\right.
$$

Game 2. When the constraints satisfy the inequalities group (37), there are also two sinks ( $E_{1}$ and $\left.E_{8}\right)$ in this tripartite evolutionary game.

$$
\left\{\begin{array}{c}
C_{1}+C_{2}+C_{s}-M-a \times b \times F_{1}<0 \\
C_{x}-M_{1}+R-a \times b \times F_{2}<0 \\
C_{3}-R_{1}<0
\end{array}\right.
$$

In the different constraints, the asymptotically stable state of the tripartite evolutionary game depends on the initial state of the system. That means the initial probabilities of three stakeholders will determine the final state of stability.

From the above analysis, it is clear that the initial ecological benefits of downstream governments ( $L_{1}$ and $L_{2}$ ) have no effect on the stability of the system. This is because the initial ecological benefits of the downstream government are a point value when the upstream government chooses different strategies. But the effect to downstream governments is a long-term process when upstream 
governments choose different strategies. As a result, the initial benefits of downstream governments are independent of the long-term process of environmental control.

\section{Numerical Simulation Results}

From the above analysis, we can see that the system has two evolutionary stabilization strategies. Next, we use numerical simulation to visually analyze the impact of changes for the initial probabilities, opportunity costs, fines, compensation fee, supervisory attitude to water resources and supervisory skills.

\subsection{Evolutionary Stable Strategy under Different Games}

\subsubsection{Evolutionary Stable Strategy under Game 1}

In this case, the constraints are shown in the inequalities group (36). There are two sinks in this tripartite evolutionary game, namely $E_{1}(0,0,0)$ and $E_{5}(1,1,0)$. So suppose $C_{1}=5, C_{2}=7, C_{3}=30$, $C_{s}=3, C_{x}=3, F_{1}=15, F_{2}=10, M=16, M_{1}=20, R=5, R_{1}=25, a=0.5, b=0.5$. Under these constraints, the overall situation of the tripartite evolutionary game is shown in Figure 3.

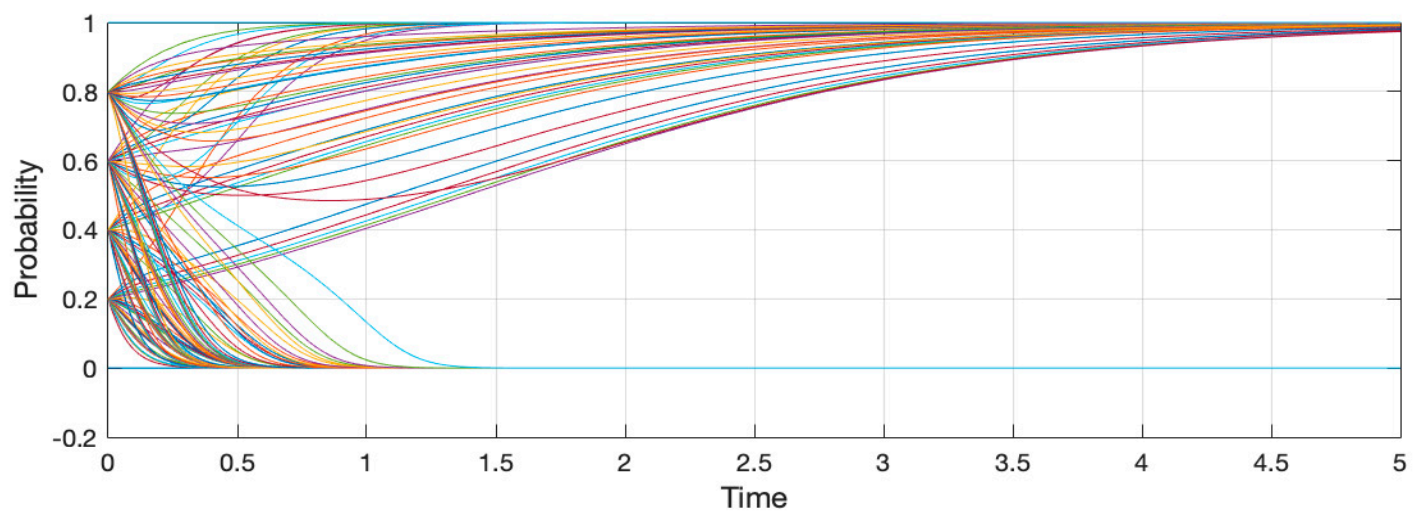

(a) Evolutionary Process of Upstream Governments

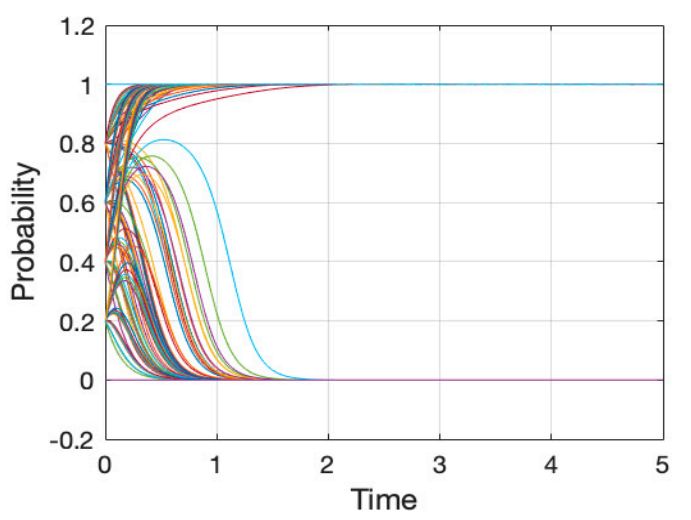

(b) Evolutionary Process of Downstream Governments

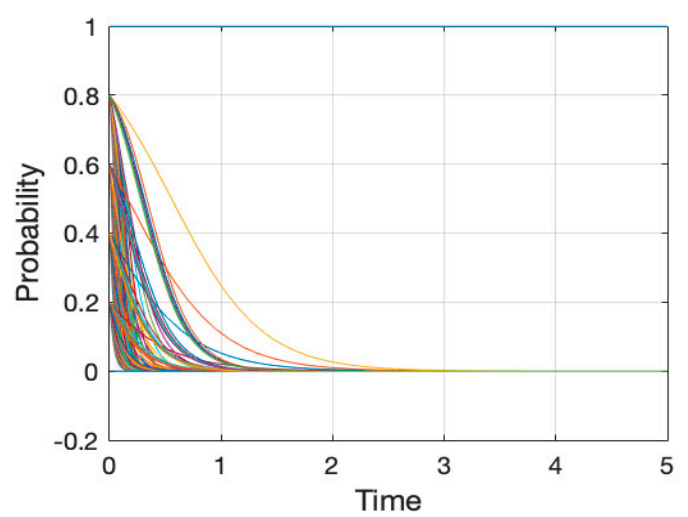

(c) Evolutionary Process of The Central Government

Figure 3. Evolutionary process of three stakeholders.

The initial value of $x, y$ and $z$ can affect the whole replicated dynamic system and the final stable statement. We divide this game into two different situations.

1. Suppose $x(0)=0.3, y(0)=0.2, z(0)=0.1$. The final result of the tripartite evolutionary game is shown in Figure $4 \mathrm{a}$. The system finally stabilizes at the point of $E_{1}(0,0,0)$. We can see clearly that upstream governments, downstream governments and the central government are stable at level 0. Upstream governments choose not to protect water resources, downstream governments choose not to pay and the central government chooses non-supervision. Meanwhile, the speed 
at which the central government reaches a stable state is the fastest, followed by upstream governments, and downstream governments are the slowest.

2. Suppose $x(0)=0.8, y(0)=0.7, z(0)=0.6$. The final result is shown in Figure $4 \mathrm{~b}$. $E_{5}(1,1,0)$ is the sink in this situation. Because the initial probabilities of upstream governments and downstream governments are high, the upstream and downstream governments elect protecting water resources and paying a compensation fee. Although the initial probability of the central government is 0.6, it still chooses non-supervision. According to Figure $4 \mathrm{~b}$, downstream governments are the fastest achieving a stable state, while upstream governments are the slowest achieving a stable state.
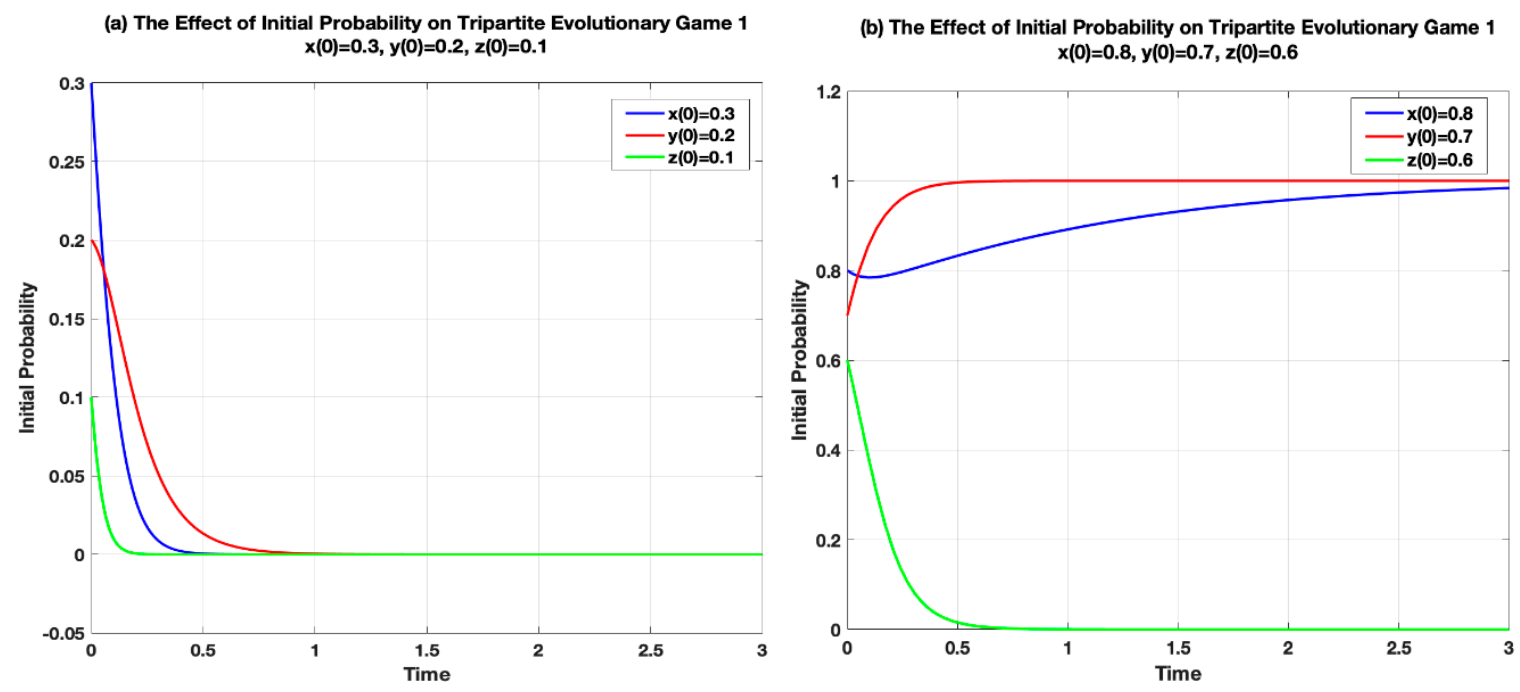

Figure 4. Effect of initial probability on tripartite evolutionary game 1.

\subsubsection{Evolutionary Stable Strategy under Game 2}

The constraints of game 2 are shown in the inequalities group (37) and there are two sinks in the replication dynamic system, namely $E_{1}(0,0,0)$ and $E_{8}(1,1,1)$, shown in Figure 5 . So, suppose $C_{1}=5, C_{2}=7, C_{3}=8, C_{s}=3, C_{x}=3, F_{1}=15, F_{2}=10, M=16, M_{1}=20, R=5, R_{1}=30$, $a=0.5, b=0.5$.

In this case, the final stable state of the replication dynamic system depends on the setting of the initial value $x(0), y(0), z(0)$. Therefore, we will analyze two groups of different initial values.

1. Suppose $x(0)=0.3, y(0)=0.2, z(0)=0.1$. The final result of the evolutionary game is shown in Figure $6 \mathrm{a}$. The system finally stabilizes at $E_{1}(0,0,0)$. It indicates that the system will finally stabilize at the point of $E_{1}$ when the initial probabilities are low. Then, upstream governments choose not to protect water resources and downstream governments choose not to pay. The central government will choose not to supervise. According to Figure 6a, we can also find that upstream governments stabilize faster, followed by the central government, and downstream governments stabilize the slowest when the initial values are low.

2. Suppose $x(0)=0.8, y(0)=0.7, z(0)=0.6$. The final result of the evolutionary game is shown in Figure $6 \mathrm{~b}$. The three stakeholders have gradually increased their willingness to cooperate, making the system stable at $E_{8}(1,1,1)$. At this point, upstream governments prefer to protect water resources and downstream governments prefer to pay for a compensation fee. The central government supervises the local governments. Through Figure $6 \mathrm{~b}$, when the initial values are high, the central government stabilizes faster, followed by the downstream government, and upstream governments stabilize the slowest. 


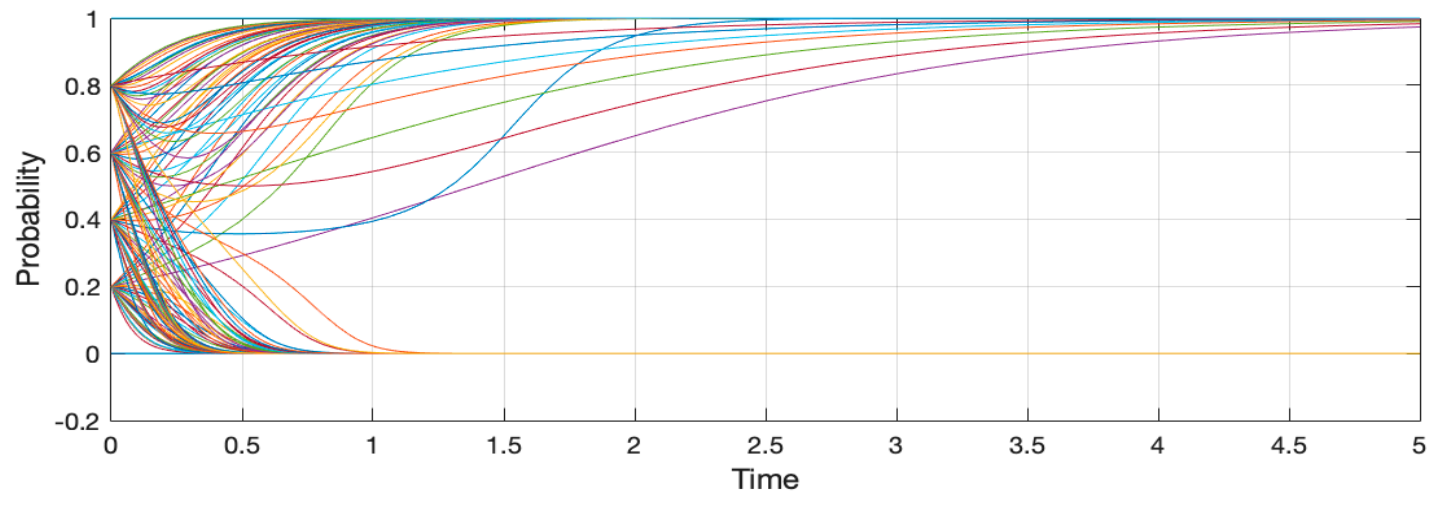

(a) Evolutionary Process of Upstream Governments

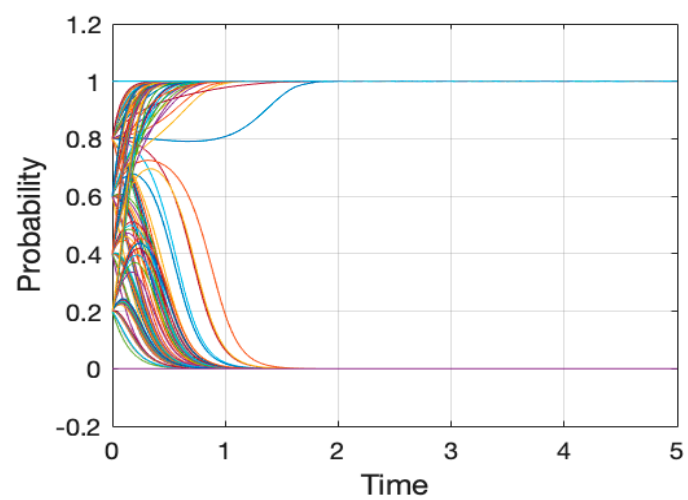

(b) Evolutionary Process of Downstream Governments

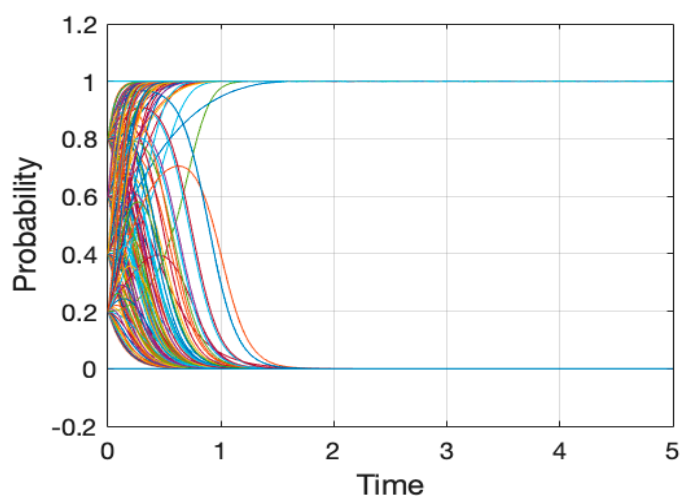

(c) Evolutionary Process of The Central Government

Figure 5. Evolutionary Process of Three Stakeholders.
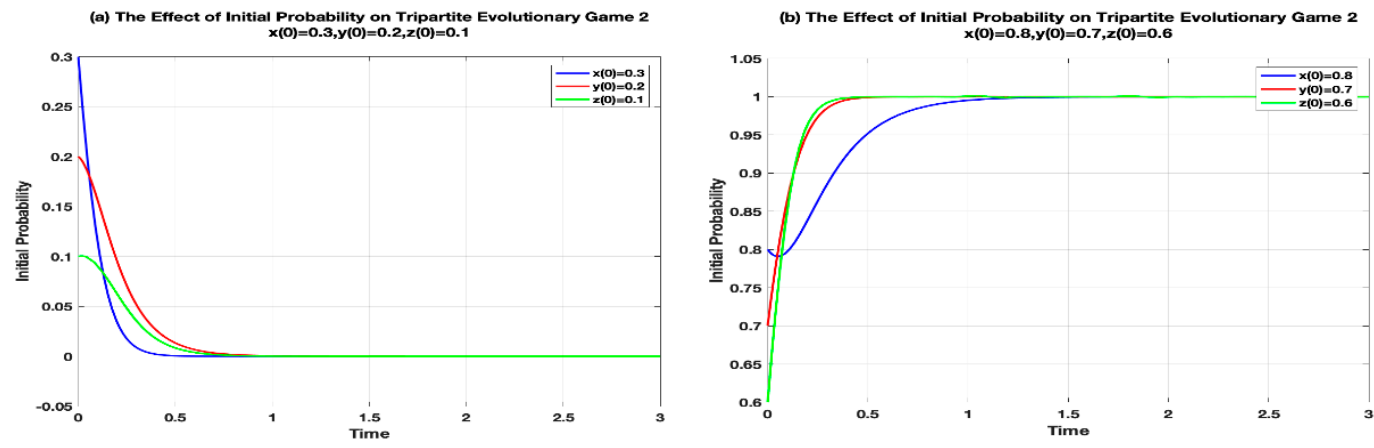

Figure 6. Effect of initial probability on tripartite evolutionary game 2.

The above results further show that the tripartite evolutionary game model constructed in this paper has two different games. The final stable state will change with different constraints. In any cases, the change of initial value will also affect the final stable state.

Therefore, the central government's supervision costs and overall benefits will affect its supervision behavior to local governments. As long as the overall benefits of the central government are less than the costs, no matter how high the initial value is, the central government will choose non-supervision.

\subsection{Parameters Analysis}

Compared to Game 1, Game 2 represents a more realistic situation that multilevel governments will participate in the watershed ecological compensation in the Eastern Route of SNWTP. Therefore, we will take Game 2 as the subject to carry out a sensitivity analysis. The parameters of opportunity 
costs $\left(C_{2}\right)$, fines $\left(F_{1}\right.$ and $\left.F_{2}\right)$, compensation fee $(R)$, supervisory attitude to water resources $(a)$, and supervisory skills $(b)$ of the central government are focused in this paper.

\subsubsection{Opportunity Costs}

In order to analyze the impact of opportunity costs on the stable state, assuming that the values of parameters are fixed except opportunity costs. So suppose $C_{1}=5, C_{3}=8, C_{s}=3, C_{x}=3$, $F_{1}=15, F_{2}=10, M=16, M_{1}=20, R=5, R_{1}=25, a=0.5, b=0.5$, and $C_{2}$ equals $4,7,10$, and 13 in turn. In order to reflect the additional effect of initial values, we take two sets of initial values, $x(0)=0.4, y(0)=0.4, z(0)=0.4$ and $x(0)=0.8, y(0)=0.8, z(0)=0.8$. The results are shown in Figure 7.

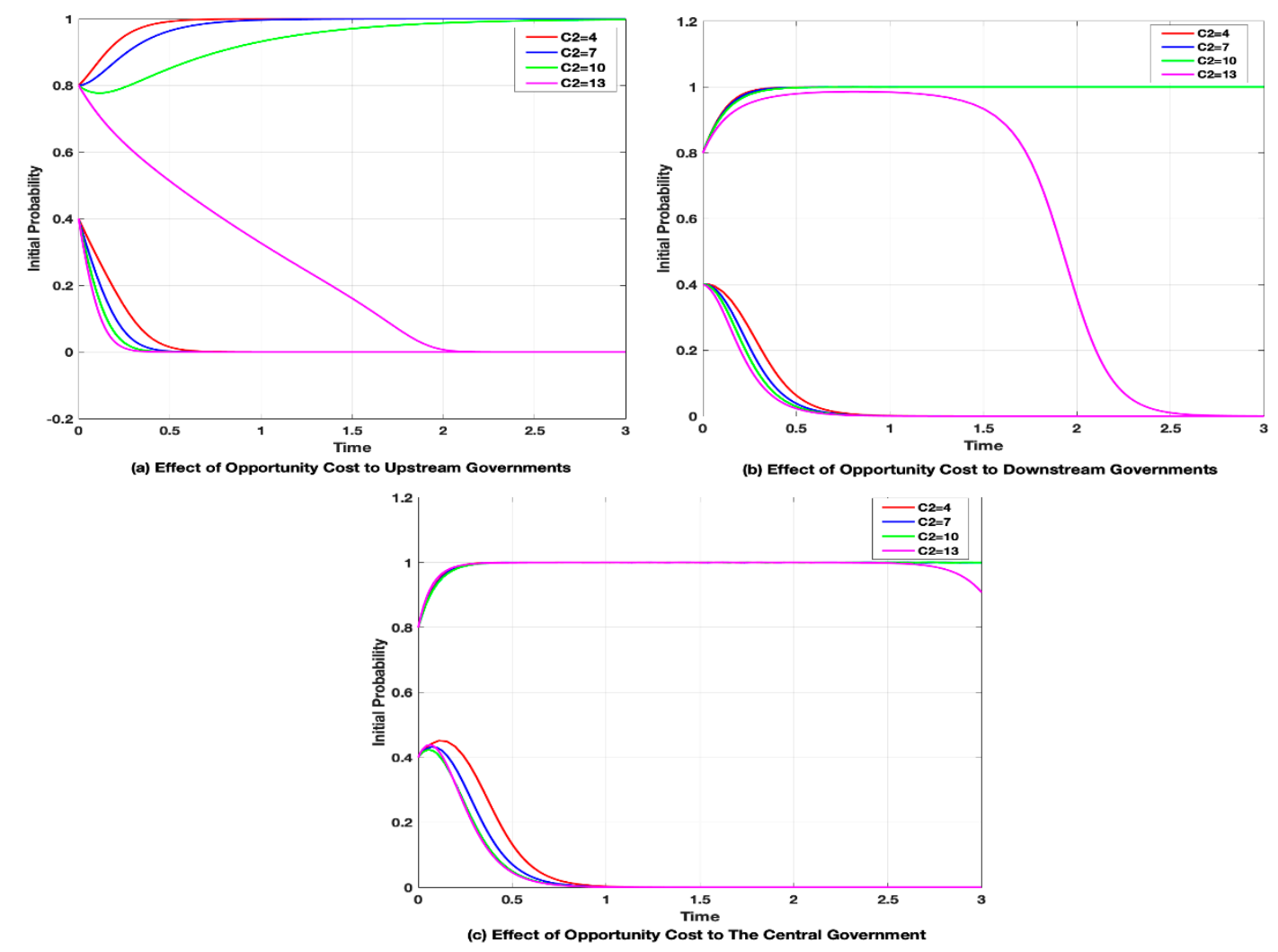

Figure 7. Effect of opportunity costs to three stakeholders.

Figure 7 illustrates the higher the opportunity costs, the faster the game finally stabilizes to state 0 , especially when the initial probabilities of three stakeholders are 0.4 . When the initial probabilities of three stakeholders are 0.8 , upstream governments choose to protect water resources at a slower pace, accompanied by increased opportunity costs. Interestingly, when the opportunity costs increase to 13 , even if upstream governments initially have a strong willingness to protect water resources, it will eventually choose not to protect water resources. The situation of downstream governments is similar to upstream governments. Opportunity costs have a small impact on the central government, especially when initial probabilities are 0.8 .

In order to protect water resources, upstream governments need to restrict the development of polluting industries and increase the investment in the infrastructure. The high opportunity costs will bring huge financial pressure to the upstream governments. Therefore, when the opportunity costs of upstream governments increase gradually, upstream governments will choose not to protect water resources. Even if the upstream governments have a high willingness to protect, they have to make such a choice under huge financial pressure. 


\subsubsection{Fines}

This paper divides the fines of the central government on local governments into two categories: the fines to upstream governments $\left(F_{1}\right)$ and to downstream governments $\left(F_{2}\right)$.

The Fines to Upstream Governments

In order to analyze the impact of $F_{1}$, assuming that the values of parameters are fixed except $F_{1}$. Suppose $C_{1}=5, C_{2}=7, C_{3}=8, C_{s}=3, C_{x}=3, F_{2}=10, M=16, M_{1}=20, R=5$, $R_{1}=25, a=0.5, b=0.5$. And $F_{1}$ equals $10,15,20$, and 100, in turn. In order to reflect the additional effect of initial values, we take two sets of initial values, $x(0)=0.4, y(0)=0.4, z(0)=0.4$ and $x(0)=0.8, y(0)=0.8, z(0)=0.8$. The results are shown in Figure 8.
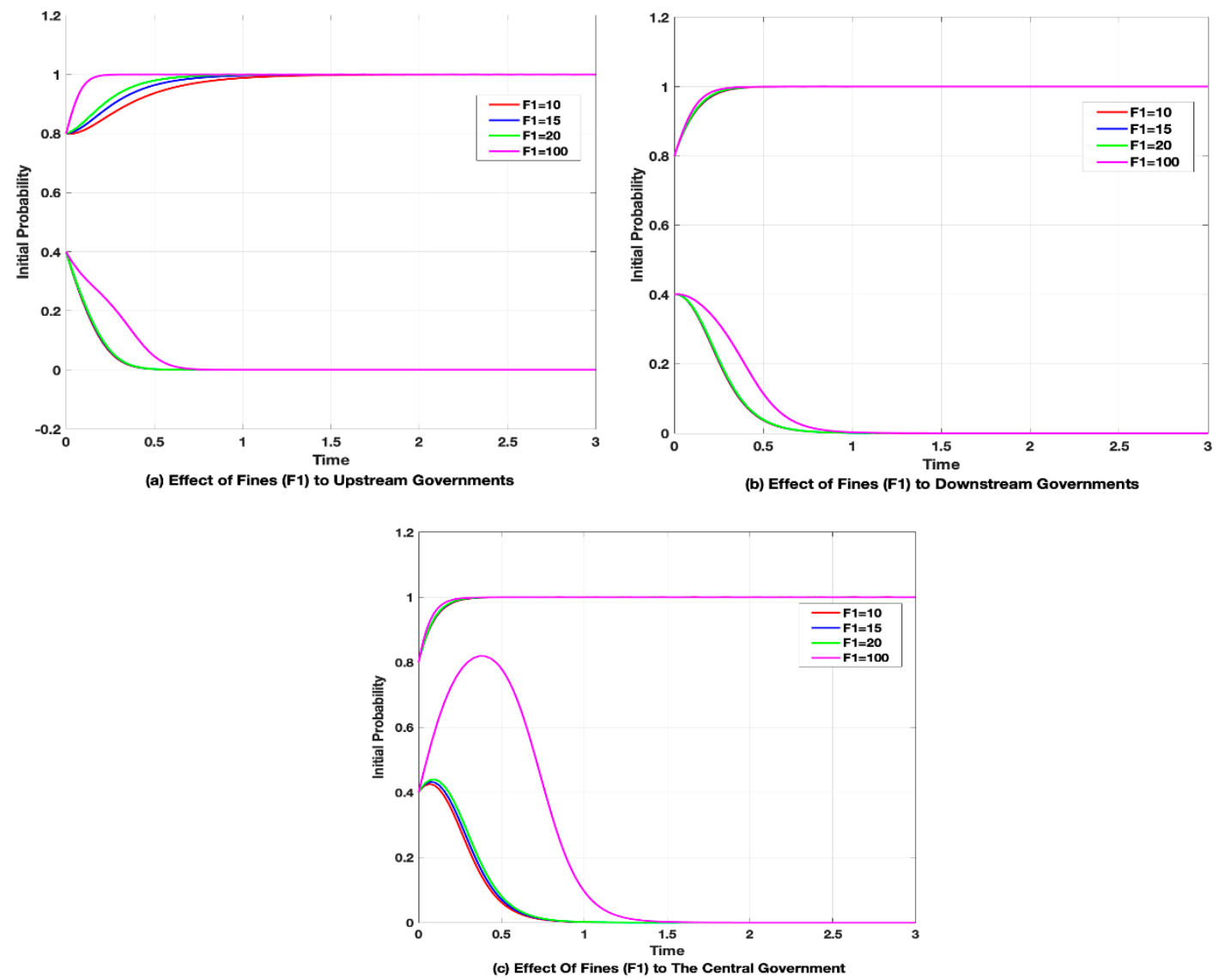

Figure 8. Effect of fines $\left(F_{1}\right)$ to three stakeholders.

Form Figure 8, obviously, when the initial probability is 0.4 , the parameter of $F_{1}$ has little effect on the three stakeholders expect the sudden change $\left(F_{1}=100\right)$. When $F_{1}$ gets 100 , upstream and downstream governments spend more time to reach state 0 and the central government is more sensitive to such changes. When the initial probability is $0.8, F_{1}$ only has a significant impact on upstream governments. The greater the fines, the quicker the stability. But it has no effect on downstream governments and the central government.

The Fines to Downstream Governments

In order to analyze the impact of $F_{2}$, we only change $F_{2}$. Suppose $C_{1}=5, C_{2}=7, C_{3}=8$, $C_{s}=3, C_{x}=3, F_{1}=10, M=16, M_{1}=20, R=5, R_{1}=25, a=0.5, b=0.5$. And $F_{2}$ equals 10, 15,20 , and 100 in turn. We take two sets of initial values, $x(0)=0.4, y(0)=0.4, z(0)=0.4$ and $x(0)=0.8, y(0)=0.8, z(0)=0.8$. The results are shown in Figure 9 . 

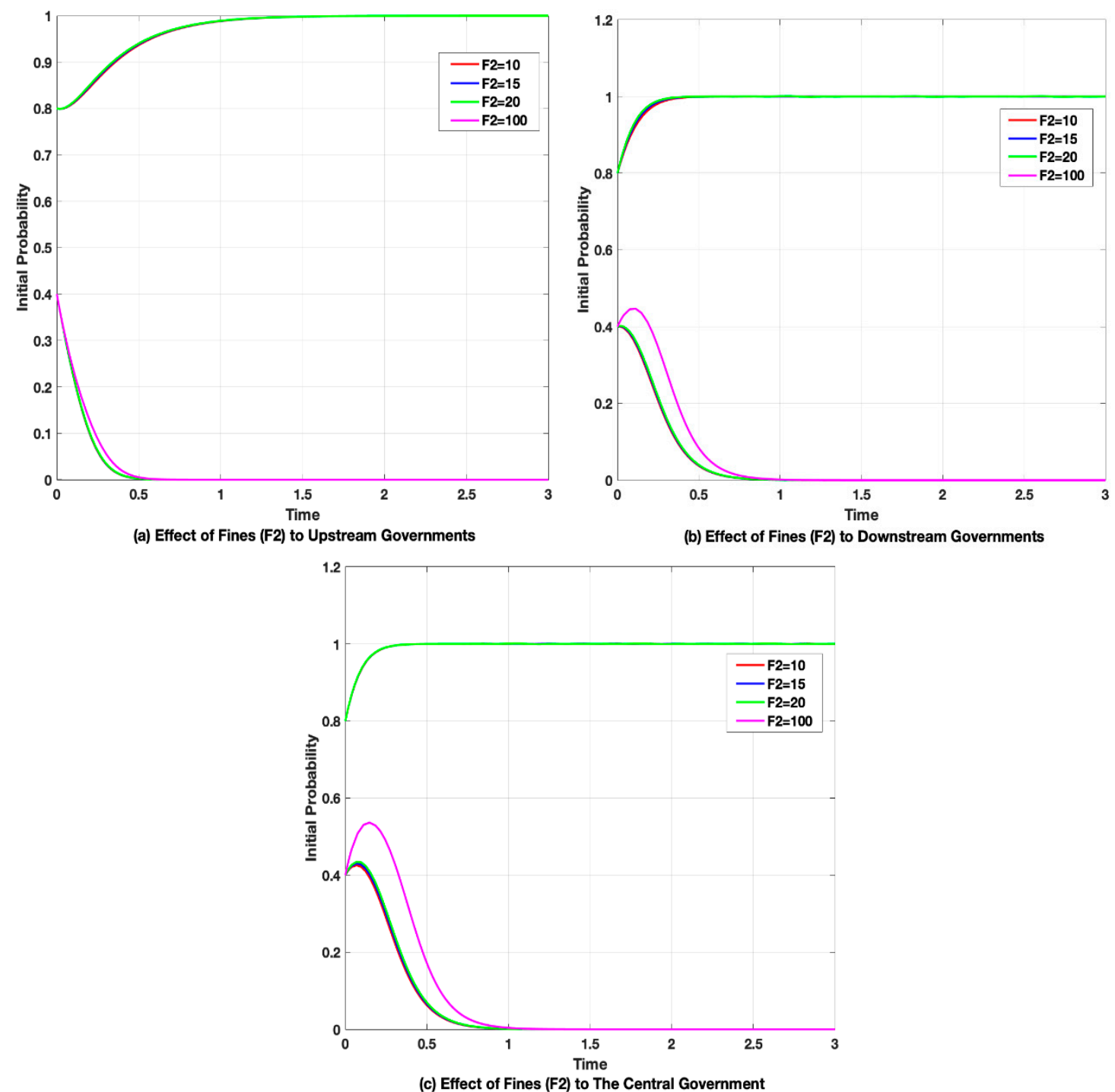

Figure 9. Effect of fines $\left(F_{2}\right)$ to three stakeholders.

According to Figure 9, we can get similar results as $F_{1}$. When $F_{2}$ increases slowly, it has little effect on the stakeholders. Only when $F_{2}$ suddenly increases $\left(F_{2}=100\right)$, the time for the stakeholders to reach a stable state will be longer and the most sensitive is the central government; the fines to downstream governments have little impact on the three stakeholders no matter how $F_{2}$ changes when the initial probability is 0.8 .

According to the analysis of fines to the local governments, punishment cannot obviously promote local governments to implement the ecological compensation system. Hence, the punishment mechanism is not an optimal choice when improving the ecological compensation system. It means that increasing punishment alone will not promote cooperation, but will reduce the probability of cooperation. It is very important to determine a reasonable punishment standard.

\subsubsection{Ecological Compensation Fee}

In this section, we suppose $C_{1}=5, C_{2}=7, C_{3}=8, C_{s}=3, C_{x}=3, F_{1}=15, F_{2}=10$, $M=16, M_{1}=20, R_{1}=25, a=0.5, b=0.5$. And $R$ equals 10,15 , and 20 in turn. In order to reflect the additional effect of initial values, we take two sets of initial values, $x(0)=0.4, y(0)=0.4, z(0)=0.4$ and $x(0)=0.8, y(0)=0.8, z(0)=0.8$. The results are shown in Figure 10 . 

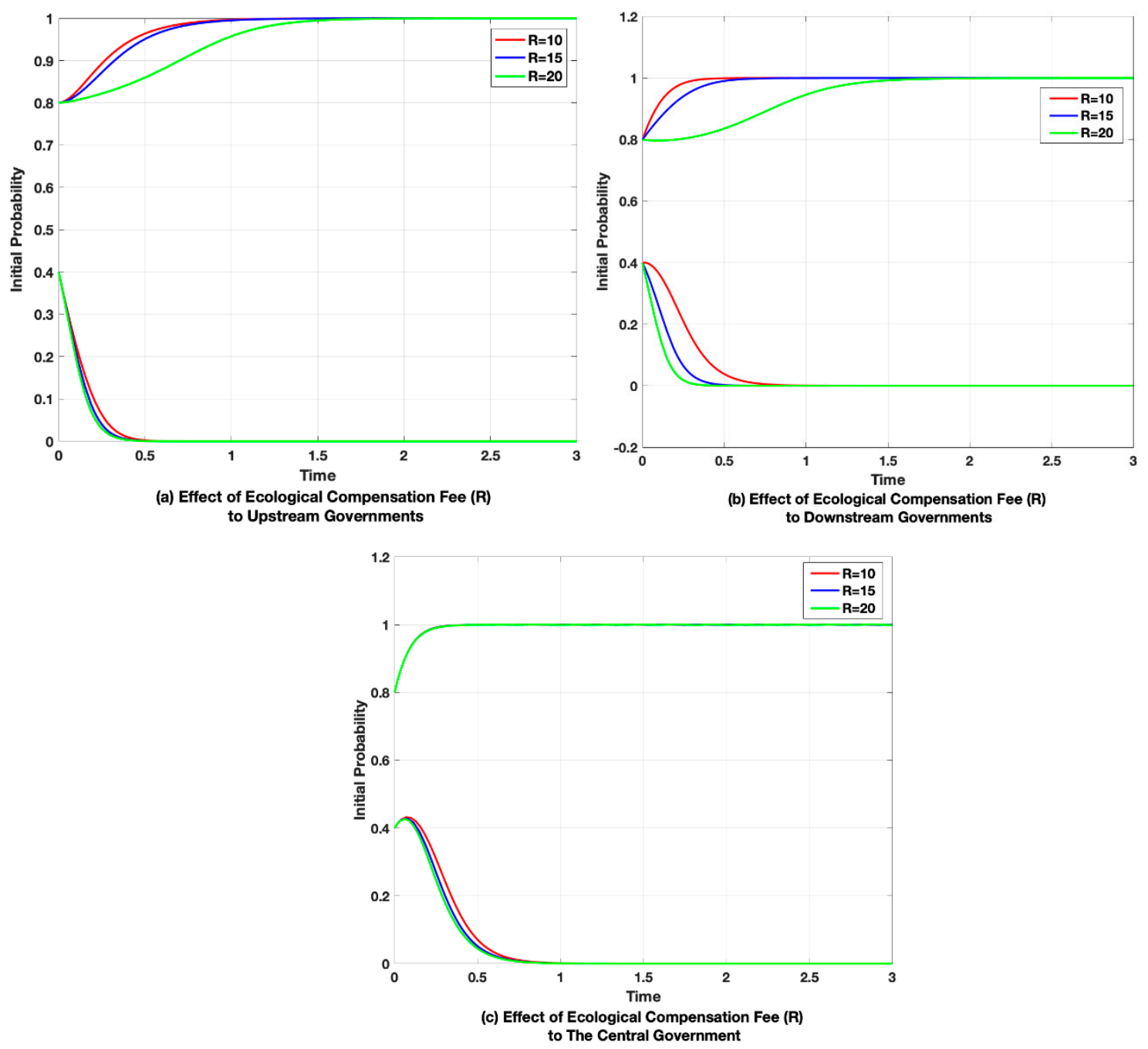

Figure 10. Effect of ecological compensation fee to three stakeholders.

According to Figure 10, when the initial probabilities are 0.4, upstream governments tend to choose a non-protection strategy, downstream governments choose non-compensation and the central government chooses non-supervision. They choose the above strategies more quickly when the ecological compensation fee increases continuously. In contrast, when the initial probability is 0.8 , the ecological compensation fee affects upstream and downstream governments but has no impact on the central government. At this time, the speed at which upstream and downstream governments choose to protect water resources and pay compensation fee slows down with the increase of ecological compensation fee.

The ecological compensation fee is a transfer payment between the upstream and downstream governments, so it has almost no impact on the central government. With the ecological compensation fee increasing, the financial press of downstream governments will increase. Therefore, it is necessary to balance the interests of upstream and downstream in order to formulate an appropriate amount of ecological compensation fee.

\subsubsection{Supervisory Attitude}

We analyze supervisory attitude to water resources as above and suppose $C_{1}=5, C_{2}=7$, $C_{3}=8, C_{s}=3, C_{x}=3, F_{1}=15, F_{2}=10, M=16, M_{1}=20, R=5, R_{1}=25, b=0.5$. And the parameter of $a$ equals $0.2,0.5,0.8$, and 5 , in turn. The results are shown in Figure 11. 


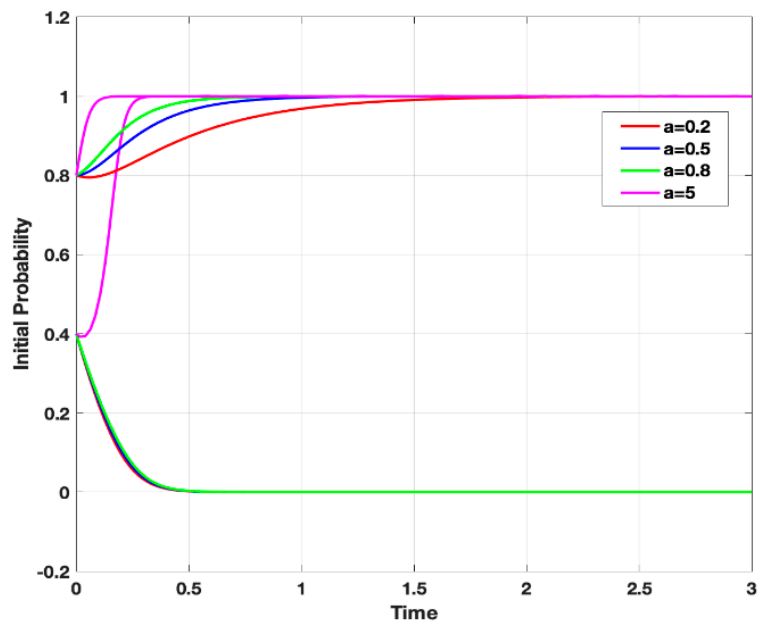

(a) Effect of Supervisory Attitude to Upstream Governments

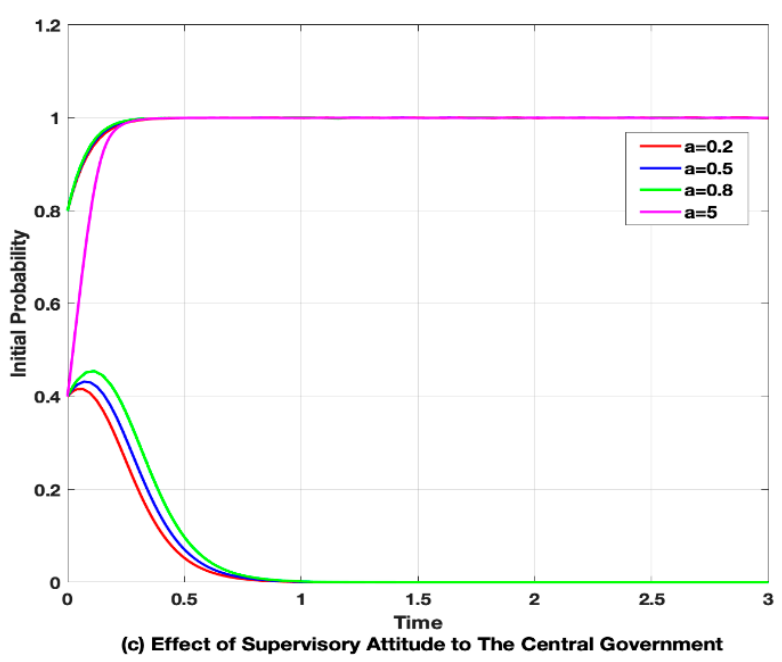

Figure 11. Effect of supervisory attitude to three stakeholders.

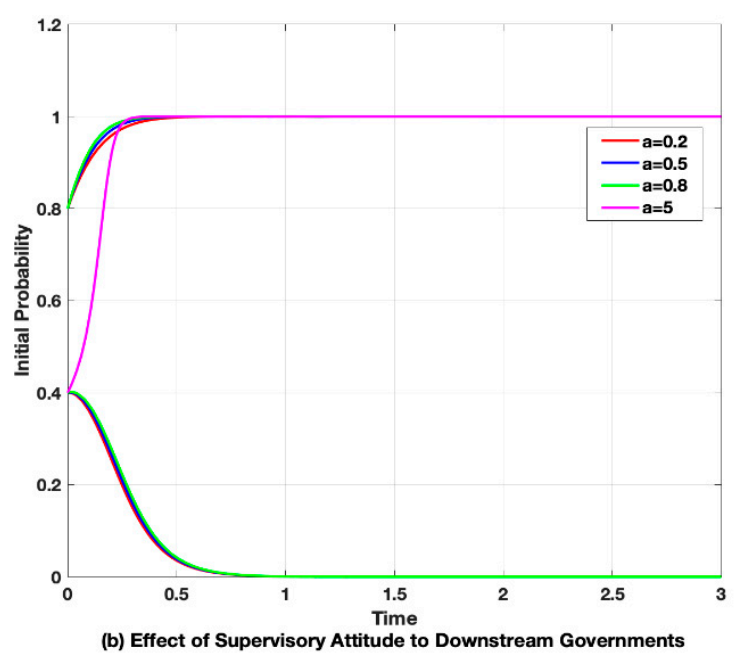

According to Figure 11, when the initial probability is 0.4 , upstream and downstream governments are insensitive to the increase of the central government's supervisory attitude. Only the central government's stabilization rate decreases with the increase of the supervisory attitude. Interestingly, when the central government's supervisory attitude increases significantly $(a=5)$, the sensitivity of the three stakeholders increases rapidly, and the stable state changes from 0 to 1 . This means that if the central government's supervisory attitude is very strong, the game will eventually stabilize at state 1 regardless of the initial probabilities of the three stakeholders. Then, upstream governments protect water resources, downstream governments pay the ecological compensation fee, and the central government supervises. In contrast, when the initial probability is 0.8 , the increasing supervisory attitude has no significant impact on downstream governments and the central government but it has a significant impact on upstream governments. With the improvement of the supervisory attitude, the speed of upstream governments stabilizing to state 1 is obviously accelerated.

The central government's supervisory attitude towards protecting the water environment reflects the central government's determination to deal with water pollution. It can effectively reflect the warning role of local governments.

\subsubsection{Supervisory Skills}

Similarly, in order to analyze the impact of supervisory skills of the central government, we assume the values of parameters are fixed except the supervisory skills $(b)$. Suppose $C_{1}=5, C_{2}=7$, $C_{3}=8, C_{s}=3, C_{x}=3, F_{1}=15, F_{2}=10, M=16, M_{1}=20, R=5, R_{1}=25, a=0.5$. And $b$ equals 0.2 , 
$0.5,0.8$ and 5 , in turn. We also take two sets of initial values, $x(0)=0.4, y(0)=0.4, z(0)=0.4$ and $x(0)=0.8, y(0)=0.8, z(0)=0.8$. The results are shown in Figure 12 .
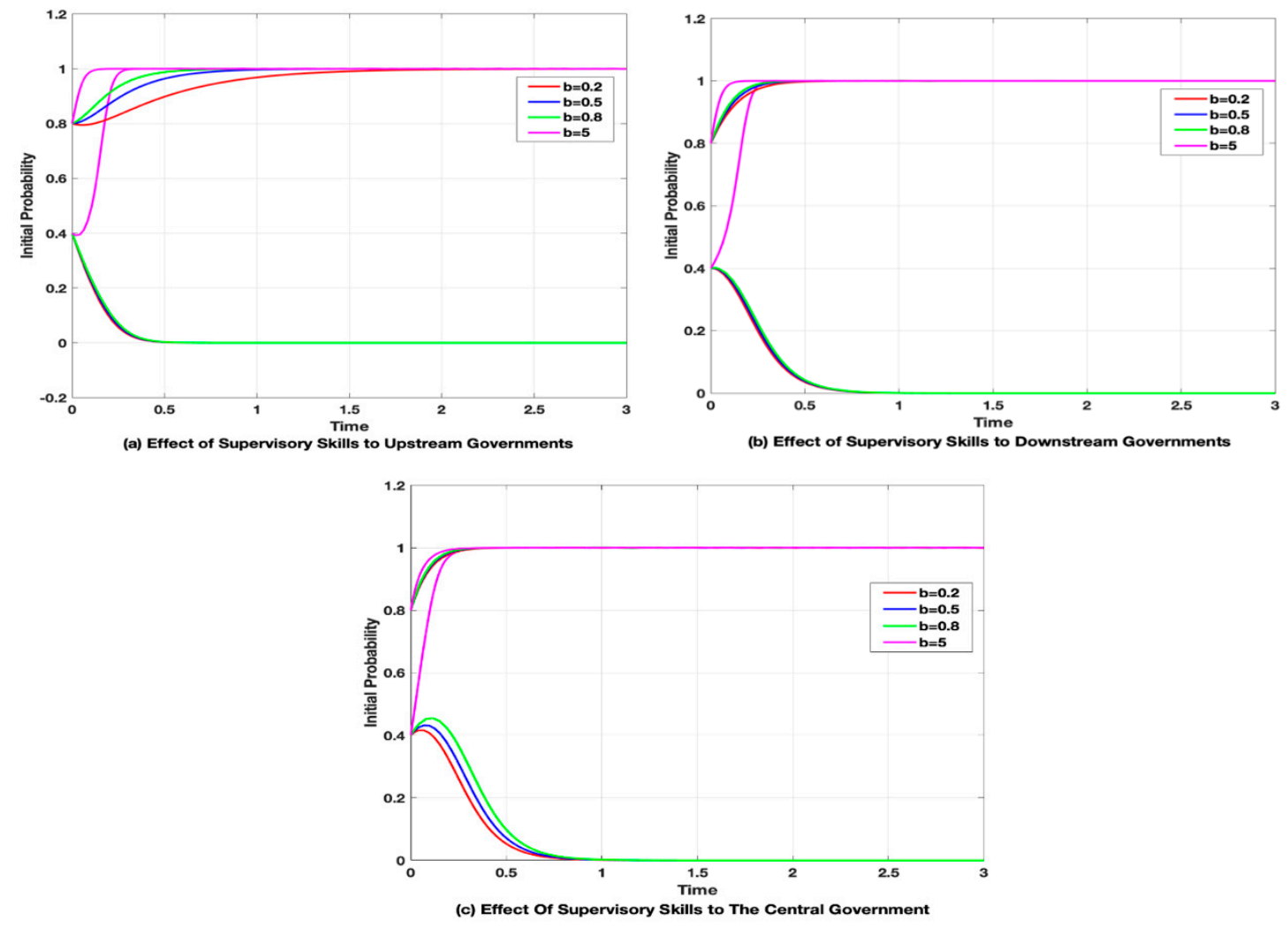

Figure 12. Effect of supervisory skills to three stakeholders.

From Figure 12, when the initial probability is 0.4, upstream and downstream governments are insensitive to the increase of the central government's supervisory skills, but the central government's speed decreases with the increase of the supervisory skills. Interestingly, when the supervisory skills of the central government increase significantly $(b=5)$, the sensitivity of the three stakeholders increases rapidly, and the stable state changes from 0 to 1 . It indicates that the increase of the central government's supervisory skills can promote the cooperation of three stakeholders regardless of their initial willing. In contrast, we can get similar results with the supervisory attitude analysis. When the initial probability is 0.8 , the increasing supervisory skills of the central government have no obvious impact on downstream governments and the central government but have a significant impact on upstream governments. With the improvement of the supervisory skills of the central government, the speed of upstream governments stabilizing to state 1 is obviously accelerated.

Supervisory skills reflect the ability of the central government to detect local governments' defaults. Improvement of the central government's supervision skills can effectively reduce the fluke mentality of local governments in breach of contract.

\section{Discussion}

Ecological civilization is the sum of material, spiritual and institutional achievements that human beings have made to protect and build a better ecological environment. It is a systematic project that runs through the whole process and all aspects of economic, political, cultural and social construction, and reflects the progress of a society's civilization. Now ecological civilization has become an important link in the harmonious development of China [60-62]. As an important part of ecological resources, water resources have received extensive attention. 
According to the results, the central government's supervision behavior is mainly affected by supervision costs and benefits. When the benefits are greater than the costs, the central government will supervise; when the benefits are less than the costs, the central government will not supervise. However, water resources are an important public product. Even if the benefits are less than the costs, the central government will not completely stop supervising local governments. Because the central government's supervision behavior is not only affected by costs and benefits but also depends on its own scope of power and responsibility. In other words, the costs and benefits will determine the supervisory power of the central government. If the benefits are greater than the costs, then the supervisory power of the central government will be enhanced; on the contrary, the supervisory power will be weakened.

In order to enhance the supervisory power of the central government, we should increase the overall benefits of the central government or reduce its supervision costs. However, it is more difficult to enhance the central government's supervisory power by increasing government benefits, so reducing supervision costs is a feasible way. Then, the central government can effectively reduce supervision costs by improving supervisory skills, streamlining government departments and carrying out "precise supervision". At the same time, the saved supervision costs can be awarded to local governments as incentives, and ultimately enhance the supervision of the central government. Therefore, it is necessary for the central government to control the supervision costs on the basis of achieving the effect of supervision.

The willingness to cooperate in local governments will directly affect the final stability of the model. If the initial willingness of upstream and downstream governments to cooperate is high, the final model will be stable in $E_{5}$. Then upstream governments choose to protect water resources and downstream governments choose to pay the ecological compensation fee. In contrast, If the initial willingness to cooperate is low, the model will eventually stabilize at $E_{1}$. Upstream governments do not protect water resources and downstream governments do not pay, which is the worst stable state in the model. Previous studies have found that ecological compensation contracts without central government regulation are not feasible. But in this study, upstream and downstream governments will cooperate regardless of whether the central government supervises or not, when the initial probability to cooperate is relatively high. It is obviously different from previous studies. The main reason is that when the upstream and downstream governments are aware of the importance of cooperation, they are more likely to form coalitions of common interest. As long as they have a strong willingness to cooperate, even without the supervision of the central government, upstream governments will protect water resources and downstream governments will compensate the upstream. Therefore, improving the willingness of cooperation between upstream and downstream is a key factor to improve the watershed ecological compensation system in the Eastern Route of the SNWTP. However, the current river basin management system in China is that governments at different levels are only responsible for their jurisdictions. The division of administrative areas leads to high supervision costs [63]. This makes upstream and downstream use water resources excessively due to different interests and ultimately leads to the breakdown of cooperation between upstream and downstream governments. At present, the river chief system implemented by the Chinese government is helping to solve the problem of the regionalization of water resources management [64]. Therefore, the implementation of river chief system in the Eastern Route of SNWTP can be helpful to break down the division of administrative areas, treating the river basin as a whole for unified management, and then strengthen the understanding of the interest community between upstream and downstream governments, so as to jointly promote the sustainable development of water resources and solve the conflict.

From the results of the numerical simulation, the level of opportunity costs will directly affect the final stable state of the tripartite game. With the increase of opportunity costs, when the initial willingness of upstream and downstream to cooperate is low, they will be stable in the state of non-cooperation. The possible reasons are with the increase in opportunity costs, upstream governments have less willingness to protect water resources and choose not to protect water 
resources. This will lead to downstream governments also choose not to pay upstream. When the initial willingness to cooperate is high, the increase in opportunity costs will reduce the speed of system stability. When opportunity costs continue to increase, they will change their strategies to no-cooperation suddenly. Therefore, it is necessary to clarify the composition of opportunity costs and weights. Only on the basis of defining the composition of opportunity costs, can we try to find appropriate ways to reduce it.

As for the fines, other scholars usually find that only increasing the fines can promote cooperation between upstream and downstream governments. Finally, the system is stable in the state of upstream governments protecting water resources and downstream governments paying a compensation fee. However, the results in this paper are different from previous studies. It is believed that the fines measure has a small significant impact on the final stability of the system, especially to upstream and downstream governments. This paper argues that fines, as a means of supervision, do not necessarily promote the system to stable at the optimal state. When the central government has a strong attitude of protecting water resources and efficient supervisory skills, the situation that upstream governments choose not to protect water resources and downstream governments choose not to pay is hard to achieve. Therefore, the fines maybe are not the optimal policy-making method, and it may be better to convert the fines mechanism into the reward mechanism [65].

The higher the ecological compensation fee, the better stability will not be achieved. The simulation shows that high ecological compensation will accelerate downstream governments to choose non-compensation strategy when the initial probability of cooperation between upstream and downstream is low. The financial pressure of downstream governments increases with the increase of the ecological compensation fee. When downstream governments choose to no-compensate, upstream governments also tend to choose not to protect water resources, which ultimately leads to the system stable in the worst state $E_{0}$. Similarly, when the initial probability of cooperation is high, we will get similar conclusions. Therefore, it is necessary to formulate an appropriate ecological compensation fee, which is too high or too low to achieve a sustainable effect. In order to implement the watershed ecological compensation in the Eastern Route of SNWTP for a long time [66], it is necessary to fully understand the object of ecological compensation. On this basis, the appropriate ecological compensation fee is worked out.

About the government's supervisory attitude to water resources and supervisory skills, the simulation results show that the slow increase of the central government's supervisory attitude to water resources and supervisory skills will not have a significant impact on the system when the initial willingness of upstream and downstream governments to cooperate is low. Interestingly, when the attitude and supervisory skills to the water resources have a significant improvement, it will lead to rapid changes from non-cooperative to cooperation. The central government's strong attitude towards protecting water resources can reflect the central government's determination to protect water resources. Meanwhile, the improvement of supervisory skills will also reduce the fluke mentality of upstream and downstream governments when they choose not to fulfill their responsibilities. This has a great warning role for the upstream and downstream governments. The central government needs to have a clear attitude towards water resources protection and improve the supervisory skills to stabilize the tripartite game at $E_{5}$ or $E_{8}$.

This paper has the following limitations: (1) The tripartite evolutionary game model constructed in this paper only applies to two local governments, for example, the Eastern Route of SNWTP involves Jiangsu Province and Shandong Province. However, it is not suitable for multi-agent watershed ecological compensation research. When this situation occurs, there is competition among different local governments. It will not only compete for the right to use water resources but also compete for the ecological compensation fee. For the central government, how to punish multiple stakeholders is difficult to solve. If we want to analyze the complex situation, we need to build a more complex model. It can be considered that using a multi-agent approach to analyze multi-participants in the watershed ecological compensation in future research. (2) This paper does not consider the allocation 
of ecological benefits. When the water environment of the basin is improved, ecological benefits are beneficial to governments at all levels. As for the allocation of ecological benefits brought about by the improvement of the water environment, it is a new direction. (3) This paper does not consider the synergistic change of multi-factors, but only considers the strategic choice of stakeholders under the single-factor change.

\section{Conclusions}

Watershed ecological compensation, as an institution that can coordinate the conflict in multilevel governments, solve transboundary water pollution, and promote the sustainable development of water resources, has been widely used. The Eastern Route of SNWTP, as a water diversion project of great strategic significance, should also use such a system to coordinate the conflict, solve transboundary water pollution and achieve the purpose of sustainable utilization of water resources. Because of the different interests in multilevel governments, building a tripartite game is helpful to analyze the problems of watershed ecological compensation. The main conclusions are as follows:

(1) The relationship between the supervision costs and benefits of the central government will affect the evolution direction of the system. When the supervisory costs are greater than the benefits, the central government will not supervise. On the contrary, the central government will supervise the local governments.

(2) The initial willingness to cooperate between upstream and downstream governments plays an important role in the evolution of the system.

(3) The fines imposed by the central government on the local governments have no significant impact on the stability of the system under any circumstances.

(4) The higher the ecological compensation fee, the higher the probability of upstream and downstream governments chose not to cooperate.

(5) The supervisory attitude to water resources and supervisory skills will have an impact on stability. When supervisory attitude and skills of the central government to water resources have been improved significantly, it will promote the local governments to change their strategies from no-cooperation to cooperation.

(6) The initial ecological benefits of downstream governments have no effect on stabilization strategies.

Based on the analysis in this paper, the following suggestions made to improve the watershed ecological compensation in the Eastern Route of SNWTP: (1) strictly follow the river chief system, eliminate the influence of administrative divisions and protect the basin as a whole; (2) add reward on the basis of fines and raise the awareness of the community of interests in order to enhance the initial willingness of cooperation between upstream and downstream governments; (3) to further analyze the composition of opportunity costs and the object of ecological compensation, determine the appropriate ecological compensation fee, and then formulate a more reasonable ecological compensation contracts; (4) maintain the stability of the central government's supervisory attitude to water resources and improve its supervisory skills, so as to increase the warning role of the central government on local governments' water resources destruction.

Author Contributions: X.G. and J.S. proposed the research ideas and methods. X.Z., Z.Z., and M.A. drew the figures. W.H., F.S., and L.Y. revised the paper.

Funding: This study was funded by the Water Conservancy Science and Technology Projects in Jiangsu Province, grant number 2018034.

Acknowledgments: The author sincerely thank the anonymous referees for their meaningful suggestions on a previous draft. This research was supported by the project from the National Natural Science Foundation of China (No. 71874101) and the 13th five-year national key research and development program funded project (No. 2016YFA0601604).

Conflicts of Interest: The authors declare no conflict of interest. 


\section{Appendix A}

The Jacobian matrix of eight equilibrium points in the replication dynamic system.

$$
\begin{aligned}
& J_{1}=\left[\begin{array}{ccc}
-C_{1}-C_{2}-C_{s} & 0 & 0 \\
0 & -C_{x}-R & 0 \\
0 & 0 & -C_{3}
\end{array}\right] \\
& J_{2}=\left[\begin{array}{ccc}
C_{1}+C_{2}+C_{s} & 0 & 0 \\
0 & M_{1}-C_{x}-R & 0 \\
0 & 0 & R_{1}-C_{3}+a \times b \times F_{2}
\end{array}\right] \\
& J_{3}=\left[\begin{array}{ccc}
\mathrm{M}-C_{1}-C_{2}-C_{s} & 0 & 0 \\
0 & C_{x}+R & 0 \\
0 & 0 & -C_{3}+a \times b \times F_{1}
\end{array}\right] \\
& J_{4}=\left[\begin{array}{ccc}
-C_{1}-C_{2}-C_{s} & 0 & 0 \\
0 & -C_{x}-R & 0 \\
0 & 0 & C_{3}
\end{array}\right] \\
& J_{5}=\left[\begin{array}{ccc}
C_{1}+C_{2}+C_{s}-M & 0 & 0 \\
0 & C_{x}-M_{1}+R & 0 \\
0 & 0 & R_{1}-C_{3}
\end{array}\right] \\
& J_{6}=\left[\begin{array}{ccc}
C_{1}+C_{2}+C_{s} & 0 & 0 \\
0 & M_{1}-C_{x}-R+a \times b \times F_{2} & 0 \\
0 & 0 & -R_{1}-C_{3}-a \times b \times F_{2}
\end{array}\right] \\
& J_{7}=\left[\begin{array}{ccc}
\mathrm{M}-C_{1}-C_{2}-C_{s}+a \times b \times F_{1} & 0 & 0 \\
0 & C_{x}+R & 0 \\
0 & 0 & C_{3}-a \times b \times F_{1}
\end{array}\right] \\
& J_{8}=\left[\begin{array}{ccc}
C_{1}+C_{2}+C_{s}-M-a \times b \times F_{1} & 0 & 0 \\
0 & C_{x}-M_{1}+R-a \times b \times F_{2} & 0 \\
0 & 0 & C_{3}-R_{1}
\end{array}\right]
\end{aligned}
$$

\section{References}

1. Umapathi, S.; Chong, M.N.; Sharma, A.K. Evaluation of plumbed rainwater tanks in households for sustainable water resource management: A real-time monitoring study. J. Clean. Prod. 2013, 42, 204-214. [CrossRef]

2. Degefu, D.M.; He, W.; Liang, Y.; Jian, H.Z. Water Allocation in Transboundary River Basins under Water Scarcity: A Cooperative Bargaining Approach. Water Resour. Manag. 2016, 30, 4451-4466. [CrossRef]

3. Degefu, D.M.; He, W.; Liao, Z.; Liang, Y.; Huang, Z.; Min, A. Mapping Monthly Water Scarcity in Global Transboundary Basins at Country-Basin Mesh Based Spatial Resolution. Sci. Rep. 2018, 8, 2144. [CrossRef]

4. Chang, S.; Qin, W.; Wang, X. Dynamic optimal strategies in transboundary pollution game under learning by doing. Phys. A Stat. Mech. Appl. 2017, 490, 139-147. [CrossRef]

5. Zhao, L.; Li, C.; Huang, R.; Si, S.; Jian, X.; Wei, H.; Yue, H. Harmonizing model with transfer tax on water pollution across regional boundaries in a China's lake basin. Eur. J. Oper. Res. 2013, 225, 377-382. [CrossRef]

6. Zhao, L. Model of collective cooperation and reallocation of benefits related to conflicts over water pollution across regional boundaries in a Chinese river basin. Environ. Model. Softw. 2009, 24, 603-610. [CrossRef]

7. Silva, E.C.D.; Caplan, A.J. Transboundary Pollution Control in Federal Systems. J. Environ. Econ. Manag. 1997, 34, 173-186. [CrossRef] 
8. Yu, X. Transboundary water pollution management Lessons learned from river basin management in China, Europe and the Netherlands. Soc. Sci. Electron. Publ. 2011, 7, 188-203. [CrossRef]

9. Sun, J.; Dang, Z.; Zheng, S. Development of payment standards for ecosystem services in the largest Interbasin water transfer projects in the world. Agric. Water Manag. 2016, 182, 158-164. [CrossRef]

10. Engel, S.; Pagiola, S.; Wunder, S. Designing payments for environmental services in theory and practice: An overview of the issues. Ecol. Econ. 2008, 65, 663-674. [CrossRef]

11. Wu, Y.; Wei, L.; Viña, A.; Luo, J.; He, G.; Ouyang, Z.; Zhang, H.; Liu, J. Performance and prospects of payments for ecosystem services programs: Evidence from China. J. Environ. Manag. 2013, 127, 86-95.

12. Lyle, G.; Bryan, B.A.; Ostendorf, B. Identifying the spatial and temporal variability of economic opportunity costs to promote the adoption of alternative land uses in grain growing agricultural areas: An Australian example. J. Environ. Manag. 2015, 155, 123-135. [CrossRef] [PubMed]

13. Porras, I.; Grieg-Gran, M.; Neves, N. All that glitters: A review of payments for watershed services in developing countries. IIED Nat. Resour. Issues 2008, 45, 420-442. [CrossRef]

14. Locatelli, B.; Vignola, R. Managing watershed services of tropical forests and plantations: Can meta-analyses help? For. Ecol. Manag. 2009, 258, 1864-1870. [CrossRef]

15. Xiong, K.; Kong, F.; Zhang, N.; Lei, N.; Sun, C. Analysis of the Factors Influencing Willingness to Pay and Payout Level for Ecological Environment Improvement of the Ganjiang River Basin. Sustainability 2018, 10, 2149. [CrossRef]

16. Na, L.; Tang, G.; Ping, Z.; Yang, H.; Gou, Y.; Kai, Y. Statistical assessment and hydrological utility of the latest multi-satellite precipitation analysis IMERG in Ganjiang River basin. Atmos. Res. 2017, 183, $212-223$. [CrossRef]

17. Chen, M.; Lu, Y.; Ling, L.; Wan, Y.; Luo, Z.; Huang, H. Drivers of changes in ecosystem service values in Ganjiang upstream watershed. Land Use Policy 2015, 47, 247-252. [CrossRef]

18. Xie, R.; Hu, F.; Pang, Y.; Zhang, N. Eco-Compensation in Multi-District River Networks in North Jiangsu, China. Environ. Manag. 2013, 51, 874-881. [CrossRef] [PubMed]

19. Xiang, S.; Shu, X.; Zhu, X.J.; Zhu, X.D.; Li, Y.F.; Li, B.L. A new indices system for evaluating ecological-economic-social performances of wetland restorations and its application to Taihu Lake Basin, China. Ecol. Model. 2015, 295, 216-226. [CrossRef]

20. State Council of the PRC. The Environmental Protection Law of the People's Republic of China. Available online: http:/ / www.npc.gov.cn/npc/xinwen/2014-04/25/content_1861279.htm (accessed on 24 April 2014).

21. Lynch, B.D. Vulnerabilities, competition and rights in a context of climate change toward equitable water governance in Peru's Rio Santa Valley. Glob. Environ. Chang. 2012, 22, 364. [CrossRef]

22. Fu, Y.; Zhang, J.; Zhang, C.; Zang, W.; Guo, W.; Qian, Z.; Liu, L.; Zhao, J.; Feng, J. Payments for Ecosystem Services for watershed water resource allocations. J. Hydrol. 2018, 556, 689-700. [CrossRef]

23. Feng, D.; Wu, W.; Liang, L.; Li, L.; Zhao, G. Payments for watershed ecosystem services: Mechanism, progress and challenges. Ecosyst. Health Sustain. 2018, 4, 13-28. [CrossRef]

24. Myerson, R.B. Game Theory: Analysis of Conflict; Harvard University Press: Cambridge, MA, USA, 1991; pp. vii-xi.

25. Qu, F.; Sun, Y. Research on Watershed Ecological Compensation Mechanism Based on Intergovernmental Game. China Popul. Resour. Environ. 2014, 1, 83-88. [CrossRef]

26. Jie, M.; Ge, Y.; Xu, G. Cooperation Evolution of Ecological Compensation between Waterhead Region and Downstream Based on Evolutionary Game. Oper. Res. Manag. Sci. 2012, 21, 137-143. [CrossRef]

27. Qian, C.; Cao, H.; Yan, H. Study on the balance mechanism of interests in marine ecological compensation. In IOP Conference Series: Earth Environmental Science Technology. Available online: https: / iopscience. iop.org/article/10.1088/1755-1315/94/1/012183 (accessed on 1 April 2019).

28. Venkatachalam, L. The contingent valuation method: A review. Environ. Impact Assess. Rev. 2004, $24,89-124$. [CrossRef]

29. Bhandari, P.; Kc, M.; Shrestha, S.; Aryal, A.; Shrestha, U.B. Assessments of ecosystem service indicators and stakeholder's willingness to pay for selected ecosystem services in the Chure region of Nepal. Appl. Geogr. 2016, 69, 25-34. [CrossRef]

30. Pietrucha-Urbanik, K.; Zelazko, A. Approaches to Assess Water Distribution Failure. Period. Polytech. Civ. Eng. 2017, 61, 632-639. [CrossRef] 
31. Peng, Z.Y.; Zhang, L.L.; Yin, J.X.; Wang, H. Study of impact factors of willingness to pay regarding water reserve of South-to-North Water Diversion Project in Beijing based on Bayesian network model. J. Clean. Prod. 2018, 184, 569-578. [CrossRef]

32. Sheng, J.; Webber, M. Incentive-compatible payments for watershed services along the Eastern Route of China's South-North Water Transfer Project. Ecosyst. Serv. 2017, 25, 213-226. [CrossRef]

33. Xie, H.; Wei, W.; Zhang, X. Evolutionary game and simulation of management strategies of fallow cultivated land: A case study in Hunan province, China. Land Use Policy 2018, 71, 86-97. [CrossRef]

34. Fan, H.; Jiang, X.; Li, C.; Yuan, Z. Complex Network Modeling and Evolutionary Game Simulation of the Arctic Environmental Emergency Response and Governance. Wirel. Pers. Commun. 2018, 102, 951-961. [CrossRef]

35. Rui, Z.; Xiao, Z.; Han, J.; Liu, C.J.T.F. For the sustainable performance of the carbon reduction labeling policies under an evolutionary game simulation. Technol. Forecast. Soc. Chang. 2016, 112, 262-274. [CrossRef]

36. State Council of the PRC. Opinions on the Implementation of the Most Stringent Water Resources Management. Available online: http:/ /www.gov.cn/zwgk/2012-02/16/content_2067664.htm (accessed on 16 February 2012).

37. Zhang, C.; Anadon, L.D. A multi-regional input-output analysis of domestic virtual water trade and provincial water footprint in China. Ecol. Econ. 2014, 100, 159-172. [CrossRef]

38. Bian, Y.; Yan, S.; Xu, H. Efficiency evaluation for regional urban water use and wastewater decontamination systems in China: A DEA approach. Resour. Conserv. Recycl. 2014, 83, 15-23. [CrossRef]

39. Zhang, Q.; Xu, Z.; Shen, Z.; Li, S.; Wang, S. The Han River watershed management initiative for the South-to-North Water Transfer project (Middle Route) of China. Environ. Monit. Assess. 2009, 148, 369-377. [CrossRef]

40. State Council of the PRC. Official Reply of the State Council on the Master Planning for the Project of Diverting Water from the South to the North. Available online: http:/ / www.gov.cn/gongbao/content/ 2003/content_62541.htm (accessed on 23 December 2002).

41. Li, J.; Zou, P.X.W. Fuzzy AHP-Based Risk Assessment Methodology for PPP Projects. J. Constr. Eng. Manag. 2011, 137, 1205-1209. [CrossRef]

42. Poethke, H.J.; Kaiser, H. A simulation approach to evolutionary game theory: The evolution of time-sharing behaviour in a dragonfly mating system. Behav. Ecol. Sociobiol. 1985, 18, 155-163. [CrossRef]

43. Ritzberger, K.; Weibull, J.W. Evolutionary Selection in Normal-Form Games. Econometrica 1995, 63, 1371-1399. [CrossRef]

44. Huang, K. Evolutionary Game and Evolutionary Economics. Econ. Res. J. 2009, 44, 132-145.

45. Lewontin, R.C. Evolution and the theory of games. J. Theor. Biol. 1961, 1, 382-403. [CrossRef]

46. Robson, A.J.; Young, H. P Individual Strategy and Social Structure: An Evolutionary Theory of Institutions. Can. J. Econ. Rev. Can. D'Econ. 1999, 3, 329-331. [CrossRef]

47. Taylor, P.D.; Jonker, L.B. Evolutionarily Stable Strategies and Game Dynamics. Math. Biosci. 1978, 40, $145-156$. [CrossRef]

48. Schmidt, C. Are evolutionary games another way of thinking about game theory? J. Evol. Econ. 2004, 14, 249-262. [CrossRef]

49. Kaniovski, Y.M.; Young, H.P. Learning Dynamics in Games with Stochastic Perturbations. Games Econ. Behav. 1995, 11, 330-363. [CrossRef]

50. Friedman, D. Evolutionary economics goes mainstream: A review of the theory of learning in games. J. Evol. Econ. 1998, 8, 423-432. [CrossRef]

51. Friedman, D. On economic applications of evolutionary game theory. J. Evol. Econ. 1998, 8, 15-43. [CrossRef]

52. Foster, D.; Young, P. Stochastic evolutionary game dynamics. Theor. Popul. Biol. 1990, 38, 219-232. [CrossRef]

53. Cressman, R.; Apaloo, J. Evolutionary Game Theory; MIT Press: Cambridge, MA, USA, 2016; pp. 847-858.

54. Smith, J.M. Evolution and the Theory of Games; Cambridge University Press: Cambridge, UK, 1982; pp. 41-45.

55. State Council of the PRC. Action Plan for Establishing Market-oriented and Diversified Mechanism for Ecological Compensation. Available online: http:/ /www.ndrc.gov.cn/zcfb/zcfbtz/201901/t2019011__ 925436.html (accessed on 28 December 2018).

56. Jin, H.; Qian, Y.; Weingast, B.R. Regional decentralization and fiscal incentives: Federalism, Chinese style. J. Public Econ. 2006, 89, 1719-1742. [CrossRef] 
57. Wainwright, J. A dynamical systems approach to Bianchi cosmologies: Orthogonal models of class A. Class. Quantum Gravity 1989, 6, 1409-1431. [CrossRef]

58. Bomze, I.M.; Weibull, J.W. Does Neutral Stability Imply Lyapunov Stability? Games Econ. Behav. 1995, 11, 173-192. [CrossRef]

59. Vadali, S.R.; Kim, E.S. Feedback control of tethered satellites using Lyapunov stability theory. J. Guid. Control Dyn. 2015, 14, 729-735. [CrossRef]

60. Wu, Q. A Study on Low-Carbon and Environmentally-Friendly Urbanization Path under the Perspective of Ecological Civilization. Adv. Mater. Res. 2014, 962-965, 1722-1725. [CrossRef]

61. He, B.J.; Zhao, D.X.; Zhu, J.; Darko, A.; Gou, Z.H. Promoting and implementing urban sustainability in China: An integration of sustainable initiatives at different urban scales. Habitat Int. 2018, 82, 83-93. [CrossRef]

62. Zhang, P.; Qin, G.; Wang, Y. Optimal Maintenance Decision Method for Urban Gas Pipelines Based on as Low as Reasonably Practicable Principle. Sustainability 2019, 11, 153. [CrossRef]

63. Cai, X. Water stress, water transfer and social equity in Northern China-Implications for policy reforms. J. Environ. Manag. 2008, 87, 14-25. [CrossRef] [PubMed]

64. Jiang, M.; Shen, X.; Wang, Y.; Wang, L. Evaluation and temporal-spatial differences of the effectiveness of the River Chief system in Jiangsu Province. South-North Water Transf. Water Sci. Technol. 2018, 16, 201-208. [CrossRef]

65. Li, H.; Zhou, L.A. Political turnover and economic performance: The incentive role of personnel control in China. J. Public Econ. 2003, 89, 1743-1762. [CrossRef]

66. Van Hecken, G.; Bastiaensen, J.; Vásquez, W.F. The viability of local payments for watershed services: Empirical evidence from MatiguÃ s, Nicaragua. Ecol. Econ. 2012, 74, 169-176. [CrossRef]

(C) 2019 by the authors. Licensee MDPI, Basel, Switzerland. This article is an open access article distributed under the terms and conditions of the Creative Commons Attribution (CC BY) license (http:/ / creativecommons.org/licenses/by/4.0/). 